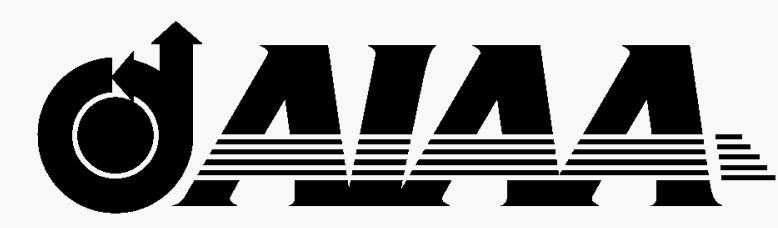

AIAA 98-3256

\title{
Static Performance of a Wing-Mounted Thrust Reverser Concept
}

Scott C. Asbury and Jeffrey A. Yetter

NASA Langley Research Center

Hampton, Virginia

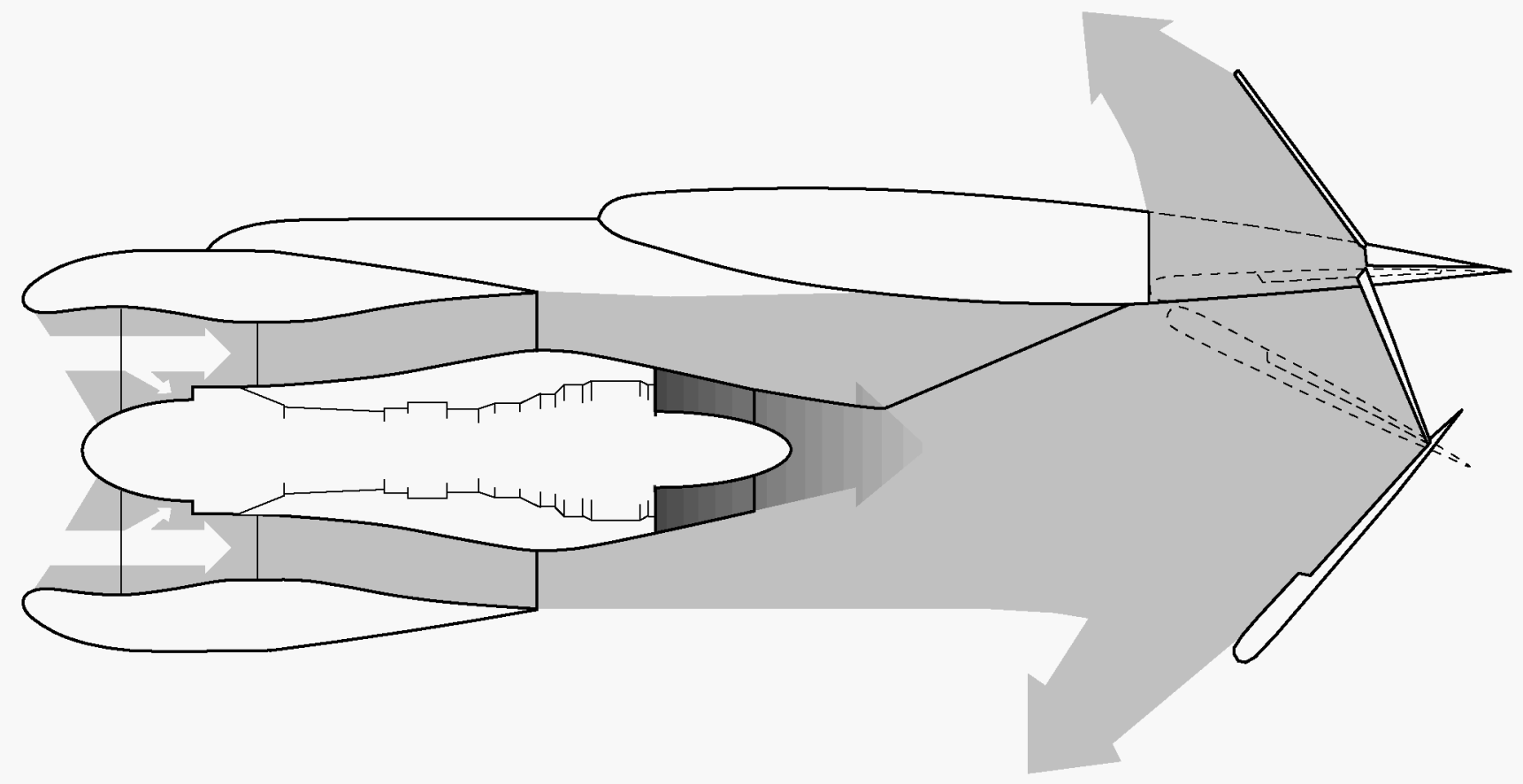

\section{4th AIAA/ASME/SAE/ASEE Joint Propulsion Conference \& Exhibit July 13-15, 1998 / Cleveland, OH}




\title{
STATIC PERFORMANCE OF A WING-MOUNTED THRUST REVERSER CONCEPT
}

\author{
Scott C. Asbury* and Jeffrey A. Yetter \\ NASA Langley Research Center \\ Hampton, Virginia
}

\begin{abstract}
An experimental investigation was conducted in the Jet-Exit Test Facility at NASA Langley Research Center to study the static aerodynamic performance of a wing-mounted thrust reverser concept applicable to subsonic transport aircraft. This innovative engine powered thrust reverser system is designed to utilize wing-mounted flow deflectors to produce aircraft deceleration forces. Testing was conducted using a $7.9 \%$-scale exhaust system model with a fan-to-core bypass ratio of approximately 9.0, a supercritical left-hand wing section attached via a pylon, and wing-mounted flow deflectors attached to the wing section. Geometric variations of key design parameters investigated for the wing-mounted thrust reverser concept included flow deflector angle and chord length, deflector edge fences, and the yaw mount angle of the deflector system (normal to the engine centerline or parallel to the wing trailing edge). All tests were conducted with no external flow and high pressure air was used to simulate core and fan engine exhaust flows.

Test results indicate that the wing-mounted thrust reverser concept can achieve overall thrust reverser effectiveness levels competitive with (parallel mount), or better than (normal mount) a conventional cascade thrust reverser system. By removing the thrust reverser system from the nacelle, the wing-mounted concept offers the nacelle designer more options for improving nacelle aerodynamics and propulsion-airframe integration, simplifying nacelle structural designs, reducing nacelle weight, and improving engine maintenance access.
\end{abstract}

\footnotetext{
* Aerospace Engineer, Configuration Aerodynamics Branch † Aerospace Engineer, High-Performance Aircraft Office

Copyright (C) 1998 by the American Institute of Aeronautics and Astronautics, Inc. No copyright is asserted in the United States under Title 17, U.S. Code. The U.S. Government has a royalty-free license to exercise all rights under the copyright claimed herein for government purposes. All other rights are reserved by the copyright owner.
}

\section{INTRODUCTION}

Although used for only a fraction of airplane operating time, the impact of thrust reverser systems on commercial aircraft nacelle design, weight, engine maintenance, airplane cruise performance, and overall operating and maintenance costs is significant. For example, the weight of a cascade-type thrust reverser system installed in a bypass ratio (BPR) 9 engine nacelle is approximately 1,500 pounds per engine. During cruise flight, losses due to flow leakage and pressure drops across stowed reverser hardware have been estimated to reduce engine specific fuel consumption by 0.5 to $1.0 \%$. Furthermore, the amortized cost of a thrust reverser system on a 767 aircraft is approximately $\$ 125,000$ per airplane per year'.

While their penalties may be significant, thrust reverser systems remain a necessary commodity for most commercial aircraft. This is because thrust reverser systems provide additional stopping force, added safety margins, and increased directional control during landing rolls, rejected takeoffs, or ground operations on contaminated runways/taxiways where wheel braking effectiveness is diminished. In fact, airlines consider thrust reverser systems essential to achieving the maximum level of aircraft operating safety ${ }^{1}$.

The cascade-type thrust reverser is commonly used on commercial aircraft equipped with high-bypass-ratio $(5<\mathrm{BPR}<9)$ turbofan engines. With the current trend progressing towards even larger turbofan engines $(B P R \approx 12$ to 15$)$, in response to demands for increased thrust levels and higher propulsive efficiency, designers are realizing that cascade-type thrust reversers may become exceedingly heavy and difficult to integrate into such large engine nacelles.

In response to a challenge from industry to provide a "technology injection" to thrust reverser design, the NASA Langley Configuration Aerodynamics Branch has completed a cooperative test program with industry to investigate innovative thrust reverser concepts that offer potential weight savings and/or design simplifications over conventional cascade reverser systems. Industry partners in this effort included Allison, BF Goodrich Aerospace, Boeing, General Electric, Northrop-Grumman, Pratt \& Whitney, and Rolls-Royce. Candidate thrust reverser concepts for 
the NASA Innovative Thrust Reverser Program were proposed jointly with the industry partners. Six of the most promising concepts (shown in figure 1) were downselected for testing. Conceptually, these systems attempt to simplify thrust reverser design, reduce reverser system weight, and/or improve overall propulsion system performance by eliminating some of the mechanisms and nacelle design compromises that cause engine performance losses during cruise operation (when the reverser hardware is stowed). These loss mechanisms include leakage, blocker scrubbing drag, linkage complexities and weight associated with the cascades, translating sleeve, blocker doors, etc.

Results from testing the cascade reverser with porous blocker (fig. 1(a)), multi-door crocodile reverser (fig. 1(b)), annular target reverser (fig. 1(c)), and fabric target reverser (fig. 1(d)) are documented in reference 2. Results from testing the blockerless reverser (fig. 1(e)) are documented in reference 3 . The purpose of this paper is to present results from tests of the wing-mounted thrust reverser concept (fig. 1(f)).

One of the limitations of fan-cowl mounted (cascade or multi-door) and core mounted (target) thrust reverser systems is that only the fan flow is reversed. With a wing-mounted thrust reverser system, both the core and fan flows can be captured and reversed, and thrust reverser effectiveness can be greatly improved. By removing the thrust reverser system from the nacelle, the wing-mounted concept offers the nacelle designer more options for improving nacelle aerodynamics and propulsion-airframe integration, simplifying nacelle structural designs, reducing nacelle weight, and improving engine maintenance access.

Conceptually, a wing-mounted thrust reverser system would use one or more flow deflectors deployed from the wing to capture and reverse the engine exhaust flow. Kinematically, these flow deflectors could operate in a variety of different ways. One possibility would be to use the airplane high-lift system to form flow deflectors by either splitting (as shown in fig. 1(f)) or overturning one or more of the flap elements. Another possibility would be to deploy the deflector(s) from the lower wing surface. The model used in this investigation is representative of a generic wing-mounted thrust reverser system.

No attempt has been made to address the practicality of the wing-mounted thrust reverser concept in regard to mechanical complexity such as actuation linkages and kinematics, structural/thermal considerations, and integration with the airplane high-lift system other than to acknowledge that these issues do exist and represent challenges to the implementation of this concept.

\section{NOMENCLATURE}

\begin{tabular}{|c|c|}
\hline BPR & bypass-ratio \\
\hline b & wingspan, $199.71 \mathrm{in.}$ \\
\hline $\mathrm{C}_{\mathrm{N}}$ & normal force coefficient \\
\hline CNPR & core nozzle pressure ratio, $\mathrm{p}_{\mathrm{t}, \text { core }} / \mathrm{p}_{\mathrm{o}}$ \\
\hline $\mathrm{C}_{\mathrm{m}}$ & pitching moment coefficient \\
\hline $\mathrm{C}_{\mathrm{n}}$ & yawing moment coefficient \\
\hline $\mathrm{C}_{\mathrm{Y}}$ & side force coefficient \\
\hline $\mathrm{c}$ & local chord length, in. \\
\hline$\overline{\mathbf{c}}$ & mean aerodynamic chord, $24.33 \mathrm{in}$. \\
\hline$d_{\max }$ & maximum nacelle diameter, $11.40 \mathrm{in.}$ \\
\hline $\mathrm{F}$ & balance measured forward thrust, lbs \\
\hline $\mathrm{F}_{\mathrm{i}}$ & ideal core+fan nozzle isentropic thrust, lbs \\
\hline $\mathrm{F}_{\mathrm{i}, \text { core }}$ & ideal core nozzle isentropic thrust, lbs \\
\hline $\mathrm{F}_{\mathrm{i}, \mathrm{fan}}$ & ideal fan nozzle isentropic thrust, lbs \\
\hline FNPR & fan nozzle pressure ratio, $\mathrm{p}_{\mathrm{t}, \text { ana }} / \mathrm{p}_{\mathrm{o}}$ \\
\hline $\mathrm{F}_{\text {rev }}$ & balance measured reverse thrust, lbs \\
\hline JETF & Jet-Exit Test Facility \\
\hline 1 & deflector chord length (see fig. 5), in. \\
\hline MS & model station, in. \\
\hline $\mathrm{NF}$ & balance measured normal force, lbs \\
\hline PM & balance measured pitching moment, in-lbs \\
\hline$p_{0}$ & test cell ambient pressure, psia \\
\hline$p_{t, \text { core }}$ & average core jet total pressure, psia \\
\hline$p_{t, \text { fan }}$ & average fan jet total pressure, psia \\
\hline $\mathrm{S}$ & full-span wing reference area, $4431.71 \mathrm{in}^{2}$ \\
\hline $\mathrm{SF}$ & balance measured side force, lbs \\
\hline WL & waterline, in. \\
\hline YM & balance measured yawing moment, in-lbs \\
\hline$\Lambda_{\text {te }}$ & wing trailing edge sweep, $16 \mathrm{deg}$ \\
\hline$\phi$ & deflector angle (see fig. 5), deg \\
\hline$\eta_{\text {rev }}$ & overall thrust reverser effectiveness \\
\hline
\end{tabular}

\section{TEST FACILITY AND PROCEDURES}

The Innovative Thrust Reverser Program was conducted in the Jet-Exit Test Facility (JETF) at NASA Langley Research Center using a separate-flow exhaust system model designed for forward and reverse thrust testing at static conditions. The facility is equipped with two independently controlled high-pressure air systems that provide both fan and core nozzle flows using a dual-flow propulsion simulation system. Test measurements included forward and reverse thrust levels, fan/core nozzle and reverser weight-flow rates, and local internal fan duct and wing/deflector surface static pressures. A description of the JETF can be found in reference 4 . 
Cruise (forward thrust) and wing-mounted thrust reverser configurations were tested at a nominal fan/core nozzle pressure ratio schedule representative of current technology high-bypass-ratio turbofan engines. Procedurally, a core nozzle pressure ratio was set and then the fan nozzle pressure ratio was varied about the nominal pressure ratio schedule $(+/-0.05)$ as shown in the following table:

\begin{tabular}{|c|c|}
\hline CNPR & FNPR \\
\hline \multirow{3}{*}{1.10} & 1.10 \\
\cline { 2 - 2 } & 1.20 \\
\cline { 2 - 2 } & 1.30 \\
\hline \multirow{3}{*}{1.20} & 1.30 \\
\cline { 2 - 2 } & 1.40 \\
\cline { 2 - 2 } & 1.50 \\
\hline \multirow{3}{*}{1.30} & 1.50 \\
\cline { 2 - 2 } & 1.60 \\
\hline \multirow{3}{*}{1.40} & 1.70 \\
\hline & 1.70 \\
\cline { 2 - 2 } & 1.80 \\
\hline \multirow{3}{*}{1.50} & 1.90 \\
\hline & 1.90 \\
\cline { 2 - 2 } & 2.00 \\
\hline
\end{tabular}

Each configuration was tested up to a maximum fan weight-flow rate of approximately $23 \mathrm{lb} / \mathrm{sec}$.

\section{MODELS DESCRIPTION}

\section{Separate-Flow Exhaust System Model}

A $7.9 \%$-scale, high-bypass-ratio, separate-flow exhaust system model designed for the NASA Langley Jet-Exit Test Facility dual-flow propulsion simulation system was built for the Innovative Thrust Reverser Program. The model core and fan nozzle contours (internal/external) were based on a preliminary $B P R \approx 9.0$ separate-flow exhaust system design provided by General Electric. The maximum nacelle diameter $\left(d_{\max }\right)$ of the model was $11.42 \mathrm{in.}$ A typical test setup of the high-bypass-ratio, separate-flow exhaust system model with the wing section installed in the forward thrust, cruise configuration is shown in figure 2.

Adapter sections at MS 21.75 were used to attach the separate-flow exhaust system model to the facility hardware and provide smooth transitions to the nozzle instrumentation sections. Choke plates installed at the downstream end of the adapter sections provided for low flow distortion in the instrumentation sections. The inner/outer duct diameters of the instrumentation sections were matched to the starting diameters of the core and fan exhaust nozzles. The primary duct was instrumented with a total pressure rake containing seven area-weighted probes. The secondary duct was instrumented with three total pressure rakes, with each rake containing four area-weighted probes. The primary and secondary ducts were also instrumented with a single jet total temperature probe.

The separate-flow exhaust system model was installed on the downstream end of the instrumentation section at MS 33.75. The core section consisted of the core nozzle, core cowl, and core plug. The core cowl was split to permit installation of the fan duct blocker for cascade reverser configurations and to facilitate modifications to the core cowl section for testing of core-mounted, target thrust reverser concepts. The fan section was comprised of the fan nozzle which was also split to facilitate installation of cascade vane sections. For structural integrity, the pylon interfaced directly with the fan nozzle.

A fully metric, instrumented, 7.9\%-scale, supercritical left-hand wing section, attached via a pylon, was fabricated for use with this model to facilitate testing of the wing-mounted thrust reverser concept. Wing geometry was based on a Boeing advanced design which, at model scale, had a full-span wing reference area (S) of $4431.71 \mathrm{in}^{2}$, wing span (b) of $199.71 \mathrm{in}$, mean aerodynamic chord ( $\bar{c})$ of $24.33 \mathrm{in}$, aspect ratio of 9.00 , taper ratio of 0.30 , and a dihedral angle of $3^{\circ}$. The separate-flow exhaust system model centerline was located at a wing semispan location $(\mathrm{b} / 2)$ of 0.35 and the wing section extended spanwise from $b / 2=0.18$ to $\mathrm{b} / 2=0.52$. The wing section was sized to extend $1.5 \mathrm{~d}_{\max }$ on either side of the nacelle centerline.

\section{Wing-Mounted Thrust Reverser Model}

A typical setup of the wing-mounted thrust reverser model is presented in figure 3. To facilitate testing of this thrust reverser concept, a portion of the wing section, extending chordwise from $0.69 \mathrm{c}$ to $1.00 \mathrm{c}$ and spanwise from $b / 2=0.225$ to $b / 2=0.475$, was removed as shown in figure 4 . This established a reverser port in the wing through which exhaust flow could be turned. A smooth bullnose radius (see fig. 3(a)), which terminated at $0.69 \mathrm{c}$, helped to efficiently turn the exhaust flow. The deflector flap system was mounted to the wing section as shown in figures 3 and 4 .

As shown in figures 4 and 5, the deflector system consisted of three deflectors (each having a width of $2.0 \mathrm{~d}_{\max }$ ), optional deflector edge fences (each having a 
height of $.03 \overline{\mathrm{c}}$ ) on each deflector, and various brackets. For deflector 1 and deflector 2, short and long deflector chord lengths were tested. Brackets holding each deflector allowed testing over a range of deflector angles as illustrated in figure 6 . The angle of each deflector $(\phi)$ is defined relative to a plane perpendicular to the nozzle centerline (thrust axis) as shown in figure 5. The design of the deflector system allowed $\phi_{1}$ and $\phi_{3}$ to be independently varied, but changes in $\phi_{2}$ at constant $\phi_{3}$ resulted in deflector 2 and deflector 3 acting as a "bucket" that moved together as a unit to capture and reverse exhaust flow. Additional brackets allowed two variations (see fig. 4) in the yaw mount angle of the deflector system: (1) normal to the nozzle centerline (thrust axis) and (2) parallel to the wing trailing edge.

\section{DATA REDUCTION}

Each data point is the average steady-state value computed from fifty frames of data taken at a rate of ten frames per second. Calibration constants were applied to the data to obtain corrected forces, moments, pressures, and temperatures. A detailed description of the procedures used for data reduction in this investigation can be found in reference 5 .

Core nozzle pressure ratio (CNPR) is defined as the average core jet total pressure $\left(\mathrm{p}_{\mathrm{t}, \mathrm{core}}\right)$, measured in the primary instrumentation section, divided by test cell ambient pressure $\left(\mathrm{p}_{\mathrm{o}}\right)$ :

$$
\mathrm{CNPR}=\mathrm{p}_{\mathrm{t}, \mathrm{core}} / \mathrm{p}_{\mathrm{o}}
$$

Fan nozzle pressure ratio (FNPR) is defined as the average fan jet total pressure $\left(\mathrm{p}_{\mathrm{t}, \mathrm{fan}}\right)$, measured in the secondary instrumentation section, divided by test cell ambient pressure $\left(\mathrm{p}_{\mathrm{o}}\right)$ :

$$
\mathrm{FNPR}=\mathrm{p}_{\mathrm{t}, \mathrm{fan}} / \mathrm{p}_{\mathrm{o}}
$$

Overall nozzle thrust efficiency $\left(F / F_{i}\right)$ in forward thrust with both the fan and core operating is defined as the ratio of balance measured forward thrust $(F)$ divided by the sum of ideal core and fan nozzle isentropic thrust $\left(\mathrm{F}_{\mathrm{i}, \text { core }}+\mathrm{F}_{\mathrm{i} \text {,fan }}\right)$ :

$$
\mathrm{F} / \mathrm{F}_{\mathrm{i}}=\mathrm{F} /\left(\mathrm{F}_{\mathrm{i}, \text { core }}+\mathrm{F}_{\mathrm{i}, \text { fan }}\right)
$$

Ideal isentropic thrust values for the core $\left(\mathrm{F}_{\mathrm{i}, \mathrm{core}}\right)$ and fan $\left(F_{i, f a n}\right)$ nozzles were computed using the measured weight-flow rate, total pressure, and total temperature of the core and fan flows, respectively. Weight-flow rate was measured using multiple-critical venturi systems, one for the primary (core) air supply and one for the secondary (fan) air supply, located in each air line upstream of the dual-flow propulsion simulation system.
With both the fan and core operating, the overall thrust reverser effectiveness parameter $\left(\eta_{\text {rev }}\right)$ is defined as the ratio of balance measured reverse thrust $\left(\mathrm{F}_{\text {rev }}\right)$ to the nozzle forward thrust (F) that was measured at corresponding fan and core nozzle pressure ratios:

$$
\eta_{\text {rev }}=F_{\text {rev }} / F
$$

Model force $\left(\mathrm{C}_{\mathrm{N}}\right.$ and $\left.\mathrm{C}_{\mathrm{Y}}\right)$ and moment $\left(\mathrm{C}_{\mathrm{m}}\right.$ and $\left.\mathrm{C}_{\mathrm{n}}\right)$ coefficients were computed using balance measured force and moments nondimensionalized by wing reference area (S), wing span (b), and mean aerodynamic chord $(\overline{\mathrm{c}})$ as follows:

$$
\begin{aligned}
& \mathrm{C}_{\mathrm{N}}=\mathrm{NF} /\left(\mathrm{p}_{\mathrm{o}} \mathrm{S} / 2\right) \\
& \mathrm{C}_{\mathrm{Y}}=\mathrm{SF} /\left(\mathrm{p}_{\mathrm{o}} \mathrm{S} / 2\right) \\
& \mathrm{C}_{\mathrm{m}}=\mathrm{PM} /\left(\mathrm{p}_{\mathrm{o}} \overline{\mathrm{c}} \mathrm{S} / 2\right) \\
& \mathrm{C}_{\mathrm{n}}=\mathrm{YM} /\left(\mathrm{p}_{\mathrm{o}}(\mathrm{b} / 2)(\mathrm{S} / 2)\right)
\end{aligned}
$$

Values of $S / 2$ and $b / 2$ were used so that the test setup would more accurately reflect a twin-engine test on a full-span wing.

\section{TEST RESULTS}

All data presented in this report were taken with both the core and fan nozzles operating over a nominal fan/core nozzle pressure ratio schedule representative of current technology, high-bypass-ratio turbofan engines. Data were taken up to the maximum operating capability of either the JETF dual-flow system (reached at $\mathrm{FNPR} \approx 2.1$ in forward thrust) or the force balance (reached at $\mathrm{FNPR} \approx 1.6$ in reverse thrust). The sawtooth characteristic of the data is due to the variation in core nozzle pressure ratio at a constant fan nozzle pressure ratio (test procedures).

\section{Forward Thrust}

Overall nozzle thrust efficiency $\left(\mathrm{F} / \mathrm{F}_{\mathrm{i}}\right)$ in forward thrust is presented in figure 7 . The overall nozzle thrust efficiency is typical of a separate flow exhaust system, varying with FNPR from a low of about 0.95 to a high of about 0.98 .

\section{Reverse Thrust}

Overall thrust reverser effectiveness $\left(\eta_{\text {rev }}\right)$ for the wing-mounted reverser model with parallel deflector mount angle, long deflector chord length, and deflector edge fences installed is presented in figure 8 for all deflector angles tested. Data for these configurations show that the highest reverser effectiveness levels $\left(\eta_{\text {rev }}\right)$ occurred for configurations with $\phi_{3}=30^{\circ}$, while the angle of deflector $2\left(\phi_{2}\right)$ had the most substantial affect on reverser effectiveness $\left(\eta_{\text {rev }}\right)$; the highest $\eta_{\text {rev }}$ occurred for configurations with $\phi_{2}$ angles of $0^{\circ}$ or less. The overall 
thrust reverser effectiveness level for configurations with $\phi_{2} \leq 0^{\circ}$ ranges from about 0.30 to 0.44 at $F N P R \approx 1.1$ and generally decreases with increasing FNPR. This performance is competitive with cascade-type thrust reverser systems which have reverser effectiveness levels on the order of 0.35 to $0.40^{6}$.

There were three deflector angle combinations that, depending on FNPR, produced the highest reverser effectiveness levels. At FNPR values from 1.1 to about 1.25 , the configuration with $\phi_{1}=60^{\circ}, \phi_{2}=-15^{\circ}$, and $\phi_{3}=30^{\circ}$ had the highest reverser effectiveness. At FNPR values from 1.25 to about 1.5 , the configuration with $\phi_{1}=60^{\circ}, \phi_{2}=0^{\circ}$, and $\phi_{3}=30^{\circ}$ had the highest reverser effectiveness. At the remaining FNPR values from 1.5 to about 1.6 , the configuration with $\phi_{1}=45^{\circ}, \phi_{2}=0^{\circ}$, and $\phi_{3}=30^{\circ}$ had the highest reverser effectiveness. Therefore, with a parallel deflector mount angle, long deflector chord length, and deflector edge fences installed, these three geometries can be considered the optimum deflector "bucket" shapes for producing the maximum level of reverse thrust in their respective FNPR range. In order to understand the effect of deflector angle and other geometry variations, these configurations will be used (whenever possible) for relative comparisons presented in this paper.

Although not shown in figure 8 , large lateral force $\left(\mathrm{C}_{\mathrm{Y}}\right)$ and moment $\left(\mathrm{C}_{\mathrm{n}}\right)$ coefficients were generated by the wing-mounted reverser configurations at the parallel deflector mount angle. This is a result of the deflector system being positioned at a yaw angle with respect to the exhaust flow (where the exhaust flow is not only reversed, but is also thrust vectored in the yaw plane). Note that lateral forces and moments would cancel on a twin engine aircraft configuration with both engines operating at the same reverse thrust condition. A single engine failure in reverse thrust would result in large unopposed $\mathrm{C}_{\mathrm{Y}}$ and $\mathrm{C}_{\mathrm{n}}$ values that would have to be compensated for by the vertical tail.

Effects of deflector 1 angle $\left(\phi_{1}\right)$. The effects of $\phi_{1}$ on wing-mounted reverser performance with parallel deflector mount angle, long deflector chord length, and deflector edge fences installed are presented in figure 9 for configurations with $\phi_{3}=30^{\circ}$. The effect of $\phi_{1}$ on $\eta_{\text {rev }}$ is most substantial at FNPR values of about 1.4 or less, with the highest reverser effectiveness occurring for $\phi_{1}=60^{\circ}$. This is not surprising, since the increased flow turning angle provided by larger values of $\phi_{1}$ would be expected to provide higher values of $\eta_{\text {rev }}$. The smaller area for thru-wing flow turning that results from larger values of $\phi_{1}$, illustrated in figure 6 , does not appear to degrade the overall reverser effectiveness.
At higher values of FNPR, differences in $\eta_{\text {rev }}$ tend to be about $3 \%$ or less and there is no consistent trend in $\eta_{\text {rev }}$ with changing $\phi_{1}$. The effect of $\phi_{1}$ on longitudinal and lateral force and moment coefficients is generally small; the only significant changes with $\phi_{1}$ occur in pitching moment coefficient $\left(\mathrm{C}_{\mathrm{m}}\right)$. The small differences in $\mathrm{C}_{\mathrm{m}}$ between configurations most likely result from changes in the reverser efflux pattern and differences in the pressure distributions across the deflectors and the wing surfaces.

Effects of deflector 2 angle $\left(\phi_{2}\right)$. The effects of $\phi_{2}$ on wing-mounted reverser performance with parallel deflector mount angle, long deflector chord length, and deflector edge fences installed are presented in figure 10 for configurations with $\phi_{1}=45^{\circ}$. The highest values of $\eta_{\text {rev }}$ typically occur for configurations with $\phi_{2}=0^{\circ}$ and the differences between other values of $\phi_{2}$ increase with increasing FNPR. For deflection angles where $\phi_{2}$ is negative, a lift force is produced on deflector 2 which increases $\mathrm{C}_{\mathrm{N}}$ and $\mathrm{C}_{\mathrm{m}}$. This is attributed to pressure differences acting on the horizontal component of the deflector. The effects of $\phi_{2}$ on lateral force and moment coefficients are generally small.

Note that more positive values of $\mathrm{C}_{\mathrm{N}}$ and $\mathrm{C}_{\mathrm{m}}$ are indicative of the tendency of the wing-mounted thrust reverser system to generate lift forces. Generally, this is undesirable for a thrust reverser concept since it would act to reduce the amount of airplane weight on the wheels, thereby reducing wheel braking effectiveness. Conversely, negative values of $\mathrm{C}_{\mathrm{N}}$ would be desirable since this would tend to increase wheel braking effectiveness by putting more of the aircraft weight on the wheels.

Effects of deflector 3 angle $\left(\phi_{3}\right)$. The effects of $\phi_{3}$ on wing-mounted reverser performance with parallel deflector mount angle, long deflector chord length, and deflector edge fences installed are presented in figure 11 for configurations with $\phi_{1}=60^{\circ}$. The effects of $\phi_{3}$ for configurations with $\phi_{2}=-15^{\circ}$ (fig. 11(a)) are substantial with significantly increased $\eta_{\text {rev }}$ and reduced $C_{N}$ and $C_{m}$ occurring for the larger values of $\phi_{3}$. Increasing $\phi_{3}$ results in a larger horizontal surface component on which exhaust pressures may act, resulting in more negative lift forces and pitching moments.

The effects of $\phi_{3}$ for configurations with $\phi_{1}=60^{\circ}$ and $\phi_{2}=0^{\circ}$ (fig. 11(b)) are smaller than that shown for configurations in figure $11(\mathrm{a})$, with increased $\eta_{\text {rev }}$ and reduced $\mathrm{C}_{\mathrm{m}}$ occurring at the smaller value of $\phi_{3}$. The effects of $\phi_{3}$ on the other force and moment coefficients are similar to those discussed above. 
Effects of deflector edge fences. The effects of deflector edge fences (installed vs. removed) on wing-mounted reverser performance with parallel deflector mount angle and long deflector chord length are presented in figure 12 for configurations with $\phi_{1}=60^{\circ}$ and $\phi_{3}=30^{\circ}$. Removing the deflector edge fences results in a substantial drop in overall reverser effectiveness but produces only small changes in force and moment coefficients. The drastic reduction in $\eta_{\text {rev }}$ that occurs when the fences are removed is a result of increased exhaust flow spreading/spillage in the lateral direction. This results in a reduced amount of exhaust flow that can be turned by the deflector into the upstream direction to produce reverse thrust. Although the deflector edge fences were relatively small (approximately 12\% of the deflector chord length), their substantial flow turning benefit significantly improved overall reverser effectiveness.

Effects of deflector chord length. The effects of deflector chord length (long vs. short) on wing-mounted reverser performance with parallel deflector mount angle and deflector edge fences installed is presented in figure 13 for configurations with $\phi_{1}=60^{\circ}$ and $\phi_{3}=30^{\circ}$. The short chord length has substantially lower overall reverser effectiveness than the long chord length. The effects of chord length on force and moment coefficients are generally small. The reduction in $\eta_{\text {rev }}$ that occurs when deflector chord length is reduced is most likely the result of exhaust flow passing below the bucket formed by deflectors 2 and 3 that cannot be captured and turned to produce reverse thrust.

Effects of deflector mount angle. The effects of deflector mount angle (parallel vs. normal) on wing-mounted reverser performance with long deflector chord length and deflector edge fences installed is presented in figure 14 for configurations with $\phi_{3}=30^{\circ}$. There are substantial increases in $\eta_{\text {rev }}$ and reductions in lateral force $\left(\mathrm{C}_{\mathrm{Y}}\right)$ and moment $\left(\mathrm{C}_{\mathrm{n}}\right)$ coefficients when the deflector system is positioned normal to the exhaust flow. This is a result of eliminating the cosine effect that acts to reduce $\eta_{\text {rev }}$ and generate $C_{Y}$ and $C_{n}$ when the deflectors are mounted parallel to the wing trailing edge.

Besides the obvious advantage of increasing overall reverser effectiveness to as high as $60 \%$, the normal deflector mount configuration would eliminate part of the concern over large asymmetric lateral forces $\left(\mathrm{C}_{\mathrm{Y}}\right)$ and moments $\left(\mathrm{C}_{\mathrm{n}}\right)$ that would occur during a single engine failure in reverse thrust. A disadvantage for the normal mount configuration would be the additional degree of articulation (rotation of the deflector flap system) that would be required with this concept. The fact that parallel deflector mount provides reverser performance competitive with a conventional cascade thrust reverser system indicates that normal deflector mount position may not be required for this to be a viable concept.

\section{CONCLUDING REMARKS}

Test results have shown that the wing-mounted thrust reverser concept achieves thrust reverser effectiveness levels competitive with (parallel mount) or better than (normal mount) a conventional cascade thrust reverser. By removing the thrust reverser system from the nacelle, the wing-mounted concept offers the nacelle designer more options for improving nacelle aerodynamics and propulsion-airframe integration, simplifying nacelle structural designs, reducing nacelle weight, and improving engine maintenance access.

It should be reiterated that no attempt has been made to address the practicality of the wing-mounted thrust reverser concept in regards to mechanical complexity such as actuation linkages and kinematics, structural/thermal considerations, and integration with the airplane high-lift system other than to acknowledge that these issues do exist and represent challenges to the successful implementation of this concept. A detailed systems study should be conducted to fully address the merits of this concept.

\section{ACKNOWLEDGMENTS}

The authors would like to acknowledge the members of the joint NASA/industry working group for their invaluable contributions to the development of the wing-mounted thrust reverser concept. We would also like to express our appreciation to the members of the NASA Langley 16-Foot Transonic Tunnel Operations Group and Research Facilities Branch who provided test support in the Jet-Exit Test Facility.

\section{REFERENCES}

1. Yetter, Jeffrey A.: Why Do Airlines Want and Use Thrust Reversers? NASA TM-109158, January 1995.

2. Yetter, Jeffrey A.; Asbury, Scott C.; Larkin, Michael J.; and Chilukuri, Krish: Static Performance of Several Novel Thrust Reverser Concepts for Subsonic Transport Applications. AIAA 96-2649, July 1996.

3. Tindell, R.H.; Marconi, F.; Kalkhoran, I.; and Yetter, J.: Deflection of Turbofan Exhaust Streams for Enhanced Engine/Nacelle Integration. AIAA 97-3152, July 1997. 
4. Staff of the Propulsion Aerodynamics Branch: $A$ User's Guide to the Langley 16-Foot Transonic Iunnel Complex, Revision 1. NASA TM-102750, 1990.

5. Mercer, Charles E.; Berrier, Bobby L.; Capone, Francis J.; and Grayston, Alan M.: Data Reduction Formulas for the 16-Foot Transonic Tunnel-NASA Langley Research Center. Revision 2. NASA TM-107646, 1992.

6. Romine, B.M., Jr.; and Johnson, W.A.: Performance Investigation of a Fan Thrust Reverser for a High By-Pass Turbofan Engine. AIAA 84-1178, June 1984. 


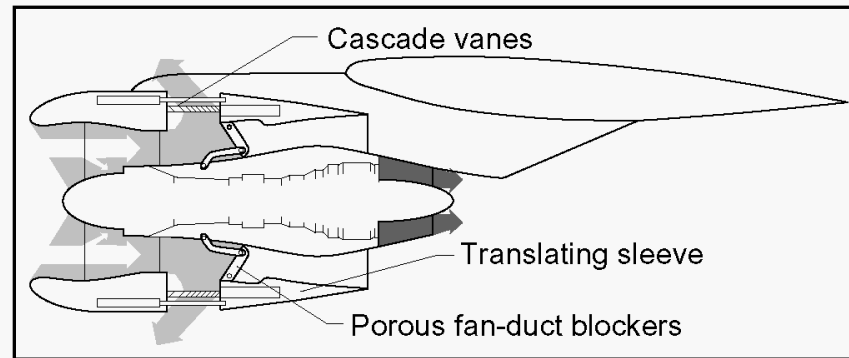

\section{(a) Cascade Reverser with Porous Blocker}

- Fan-cowl mounted stow/deploy and blocker mechanisms - Porous fan-duct blockers offer reduced blocker weight

- Fan flow reversed

\section{(b) Multi-Door Crocodile Reverser}

- Fan-cowl mounted stow/deploy mechanisms

- 8 reverser ports around fan cowl circumference

- 8 inner and outer door sets block and reverse flow

- Fan flow reversed
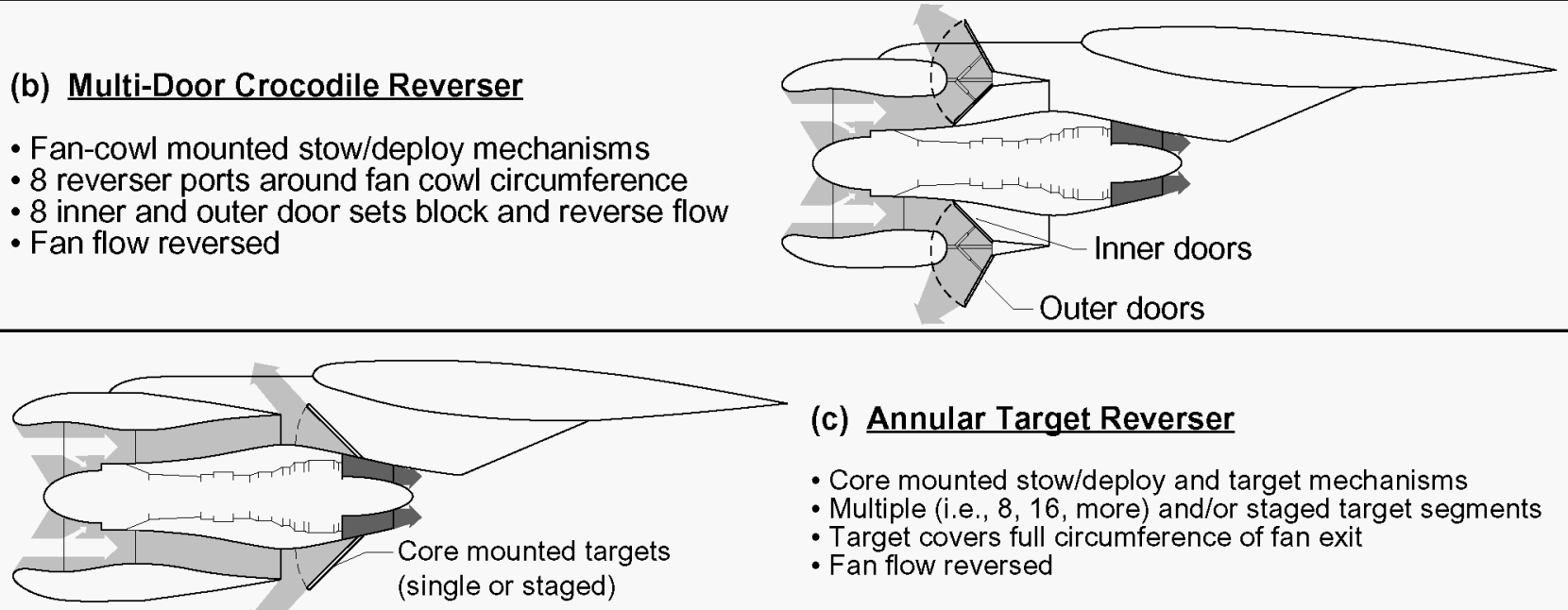

(c) Annular Target Reverser

- Core mounted stow/deploy and target mechanisms

- Multiple (i.e., 8, 16, more) and/or staged target segments

- Target covers full circumference of fan exit

- Fan flow reversed

\section{(d) Fabric Target Reverser}

- Core mounted stow/deploy and target mechanisms

- Light-weight fabric target with reel-out/take-up spools

- Target covers full circumference of fan exit

- Fan flow reversed
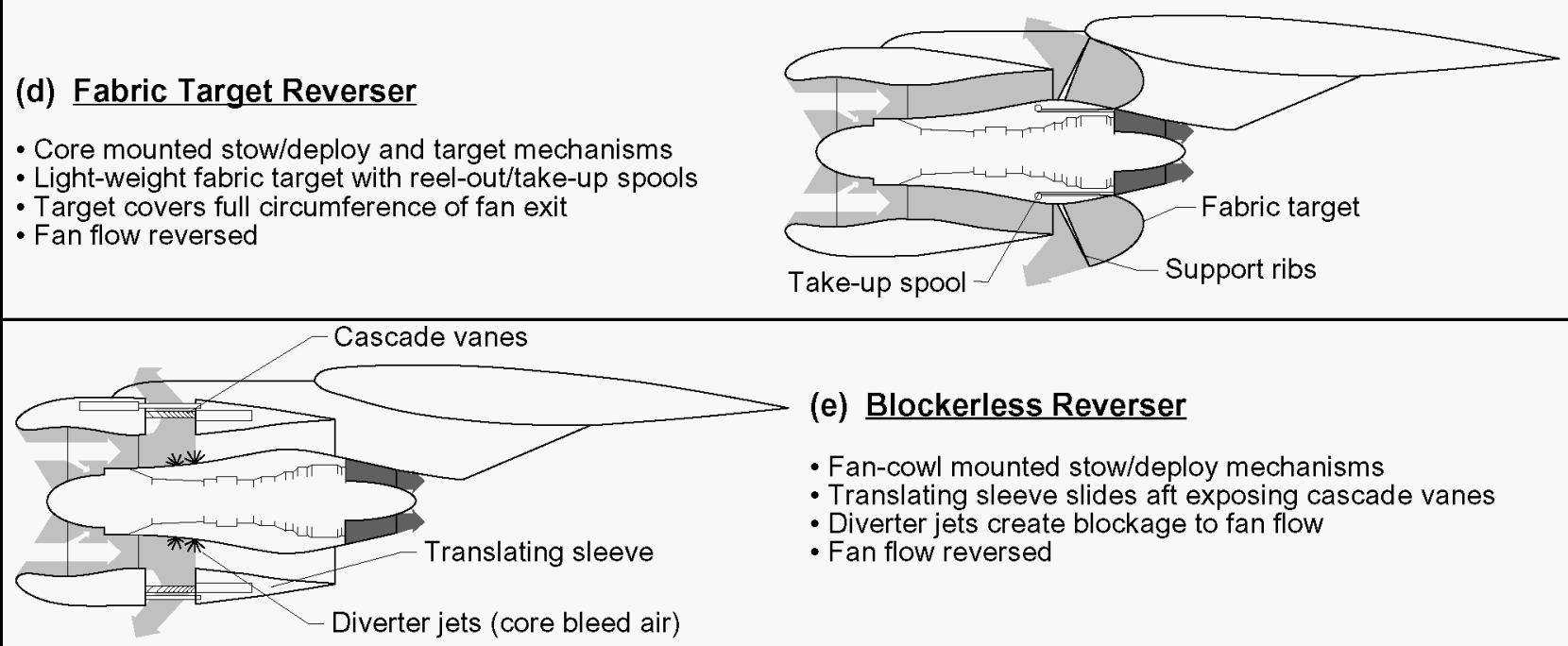

(e) Blockerless Reverser

- Fan-cowl mounted stow/deploy mechanisms

- Translating sleeve slides aft exposing cascade vanes

- Diverter jets create blockage to fan flow

- Fan flow reversed

\section{(f) Wing-Mounted Reverser}

-Wing-mounted stow/deploy mechanisms - Deflectors deploy into engine exhaust flow

- Fan and core flow reversed

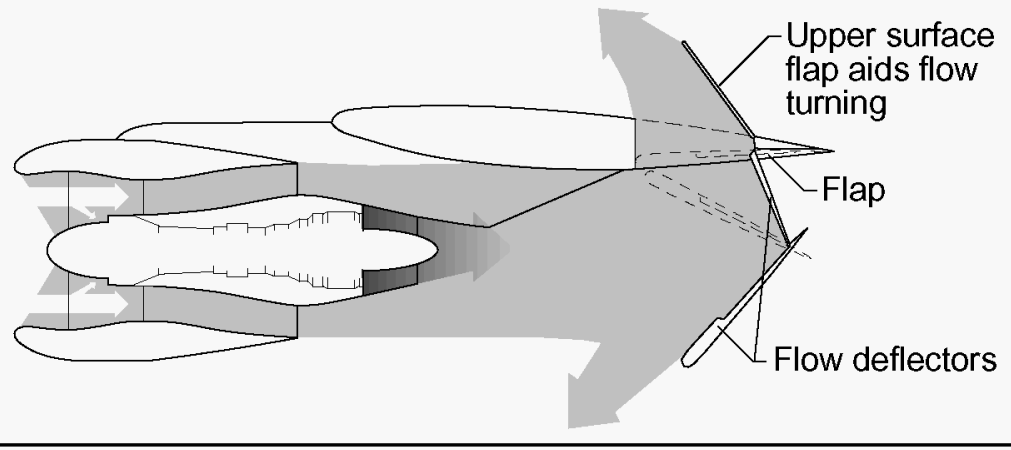

Figure 1. Sketch showing six thrust reverser concepts tested during the Innovative Thrust Reverser Program. 


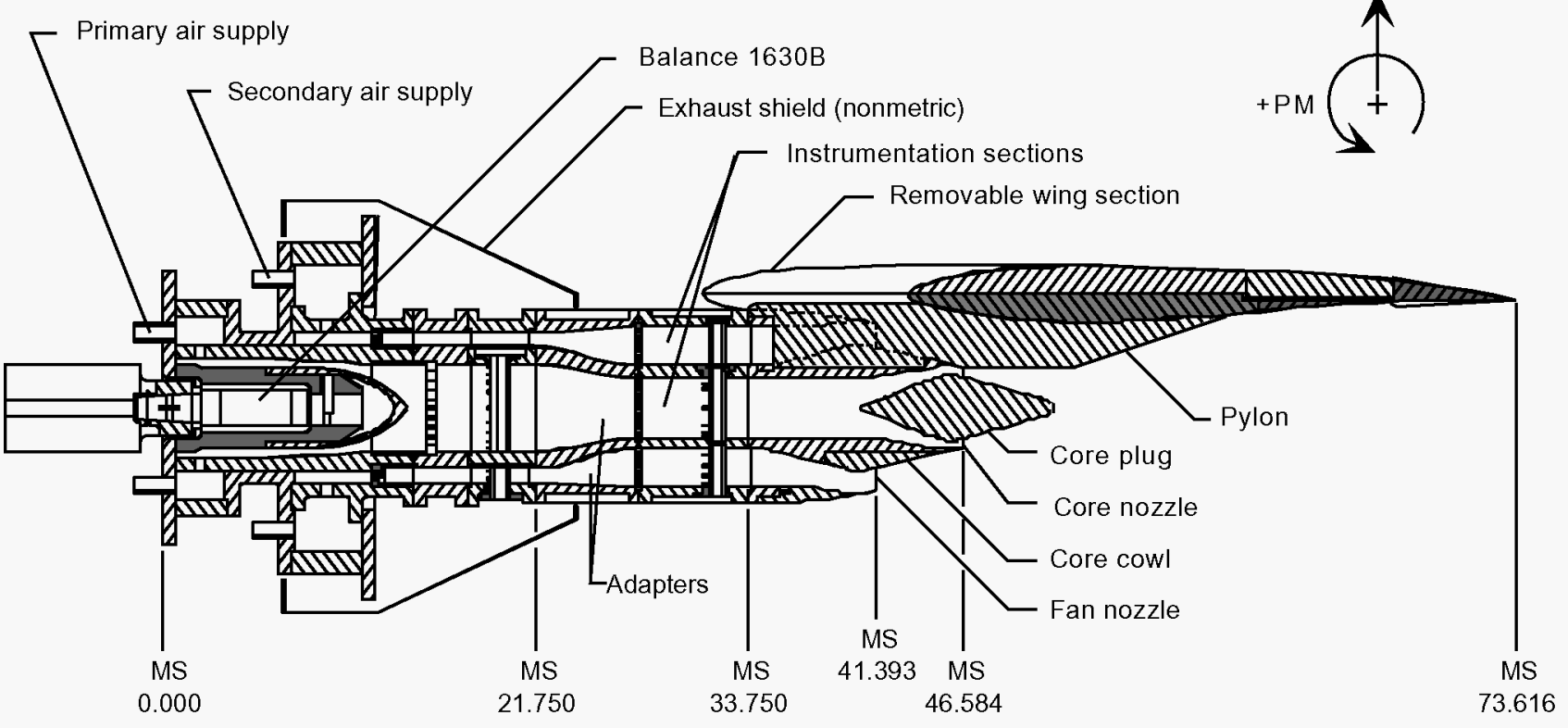

(a) Sketch showing model installation on the dual-flow propulsion simulation system.

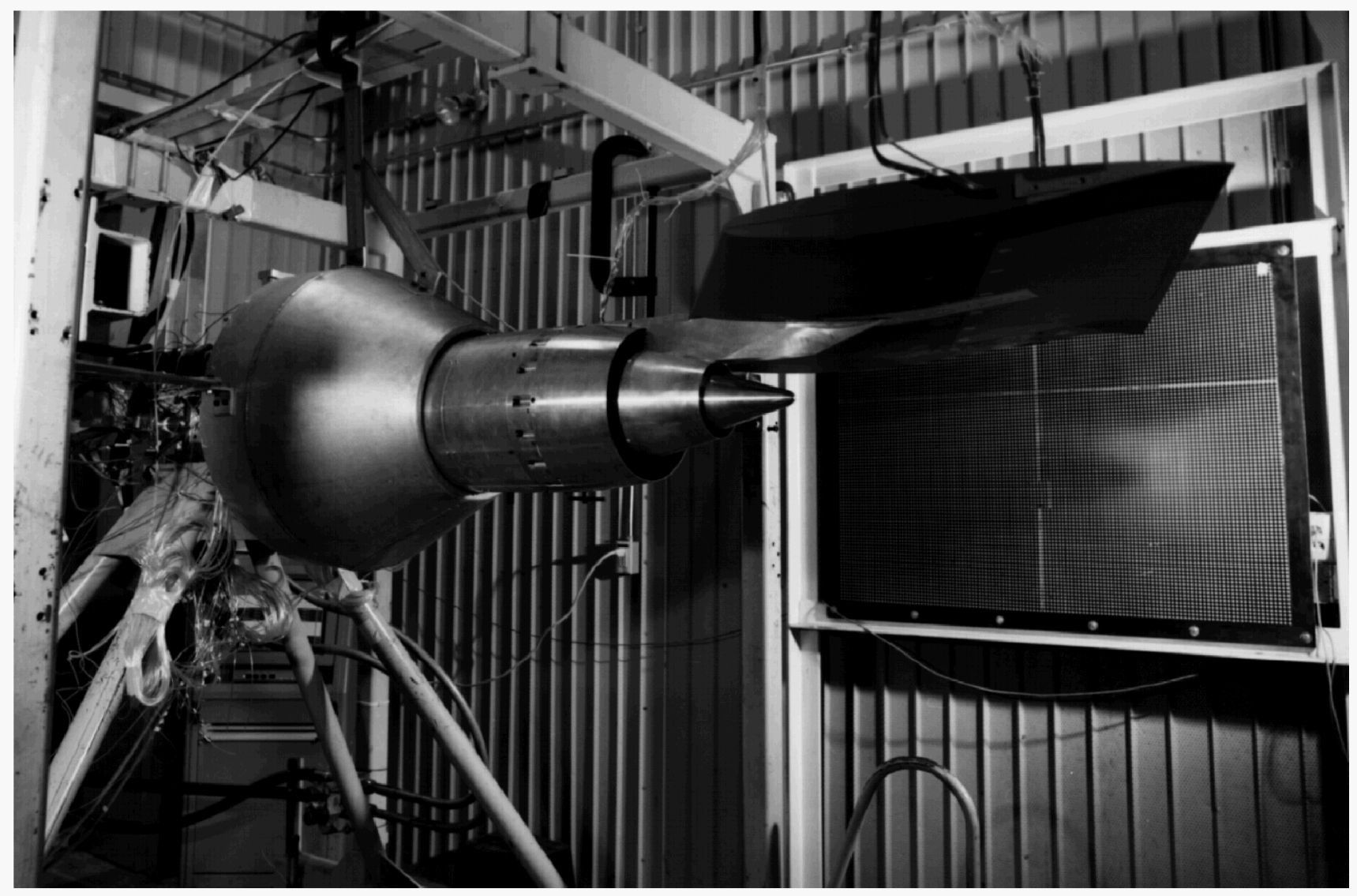

(b) Photograph of model installation in the Jet-Exit Test Facility.

Figure 2. Typical setup of separate-flow exhaust system model with the wing section installed in the forward thrust, cruise configuration. 


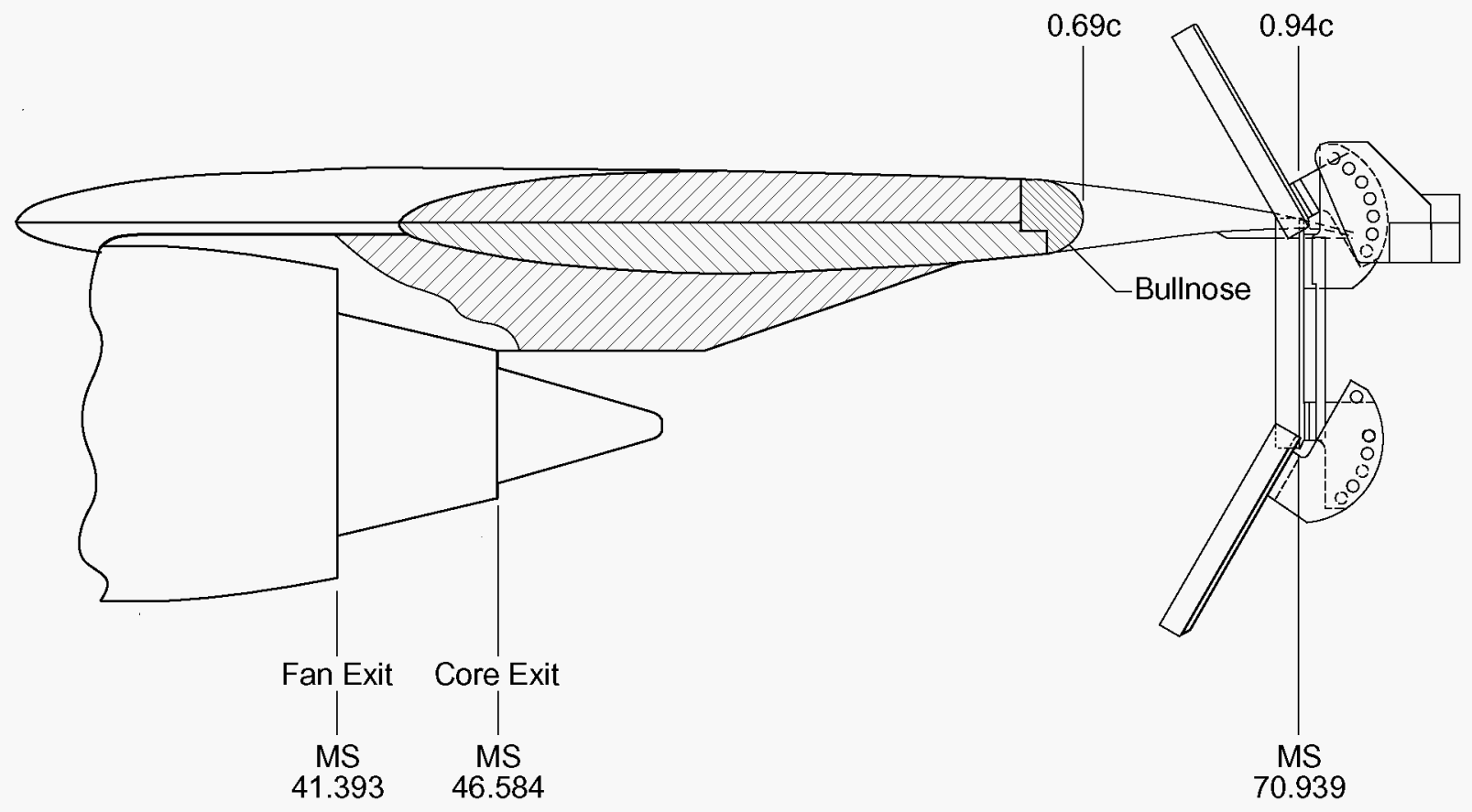

(a) Partial cutaway sketch showing details of model installation.

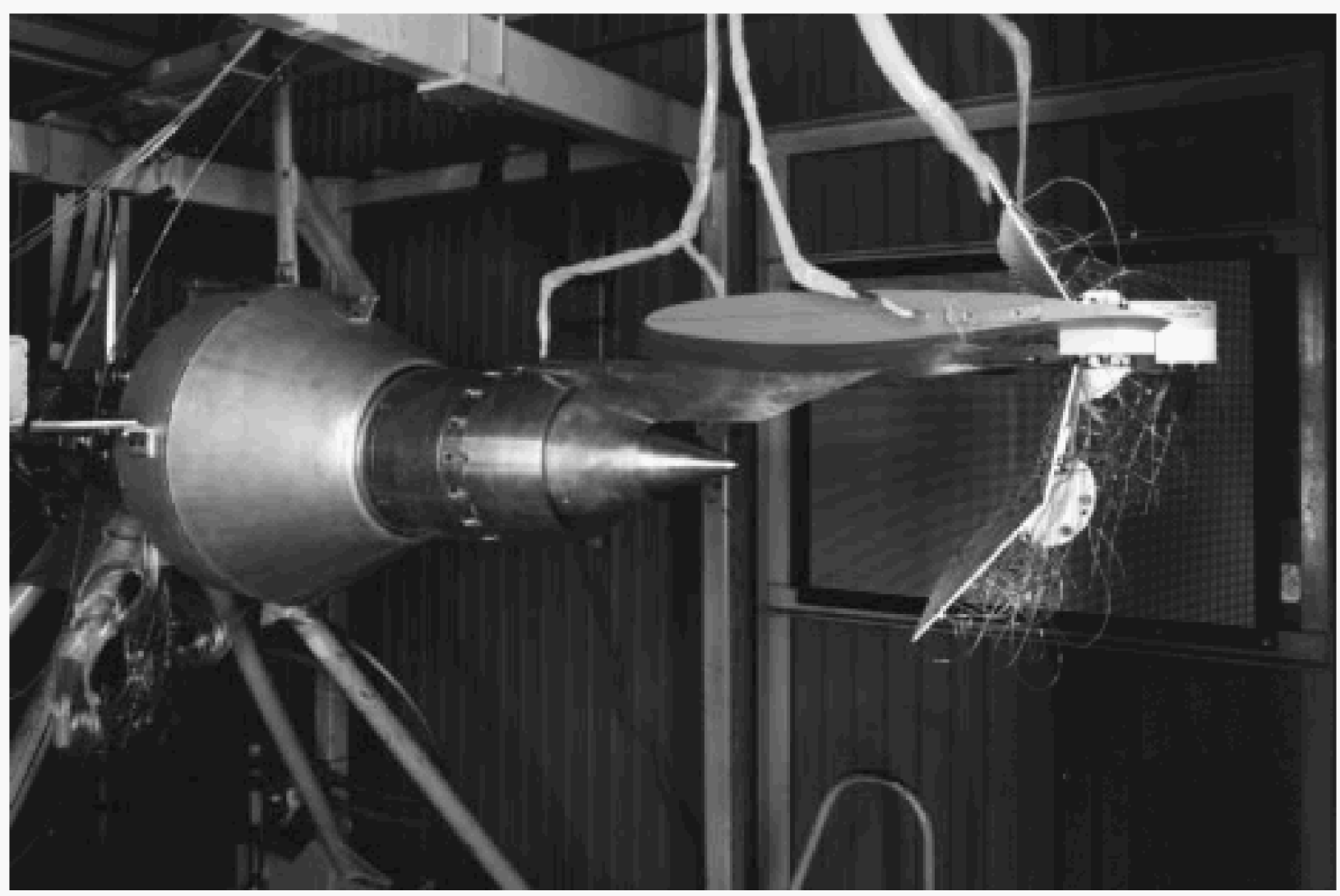

(b) Photograph of model installation in the Jet-Exit Test Facility.

Figure 3. Typical setup of wing-mounted thrust reverser model . 


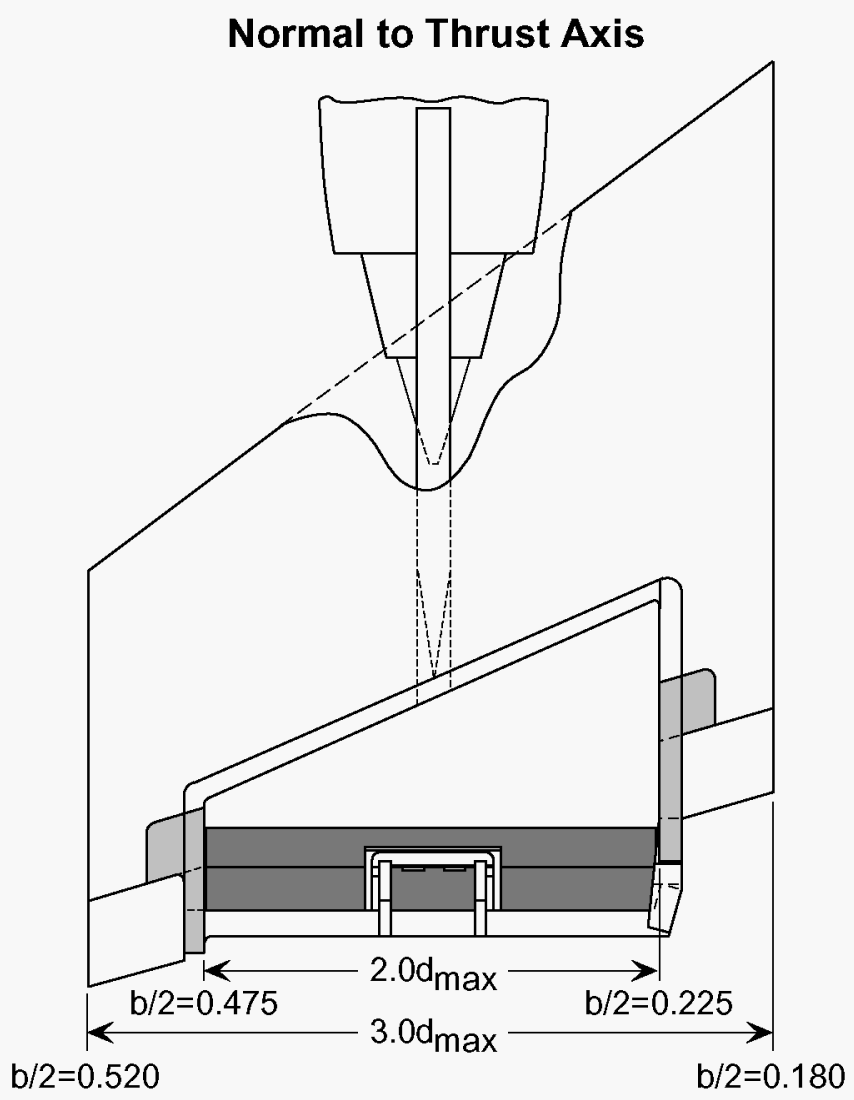

Parallel to Wing Trailing Edge

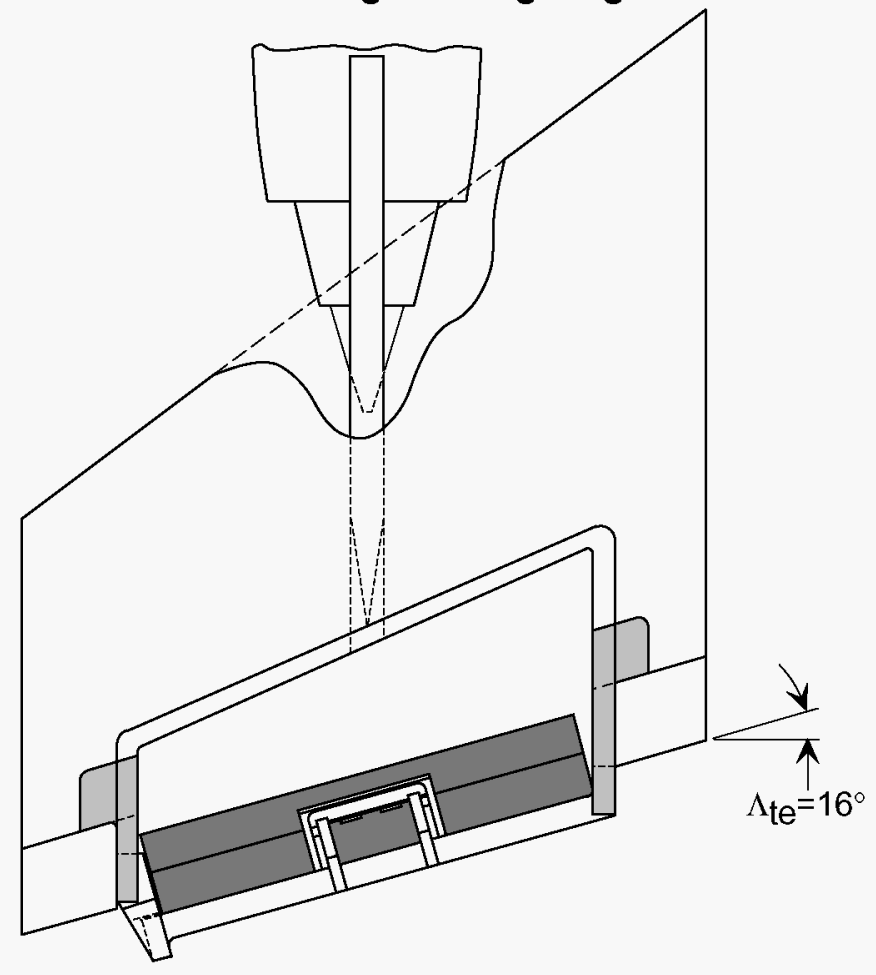

Figure 4. Sketch showing top view of wing section with deflector system installed in the normal and parallel positions.

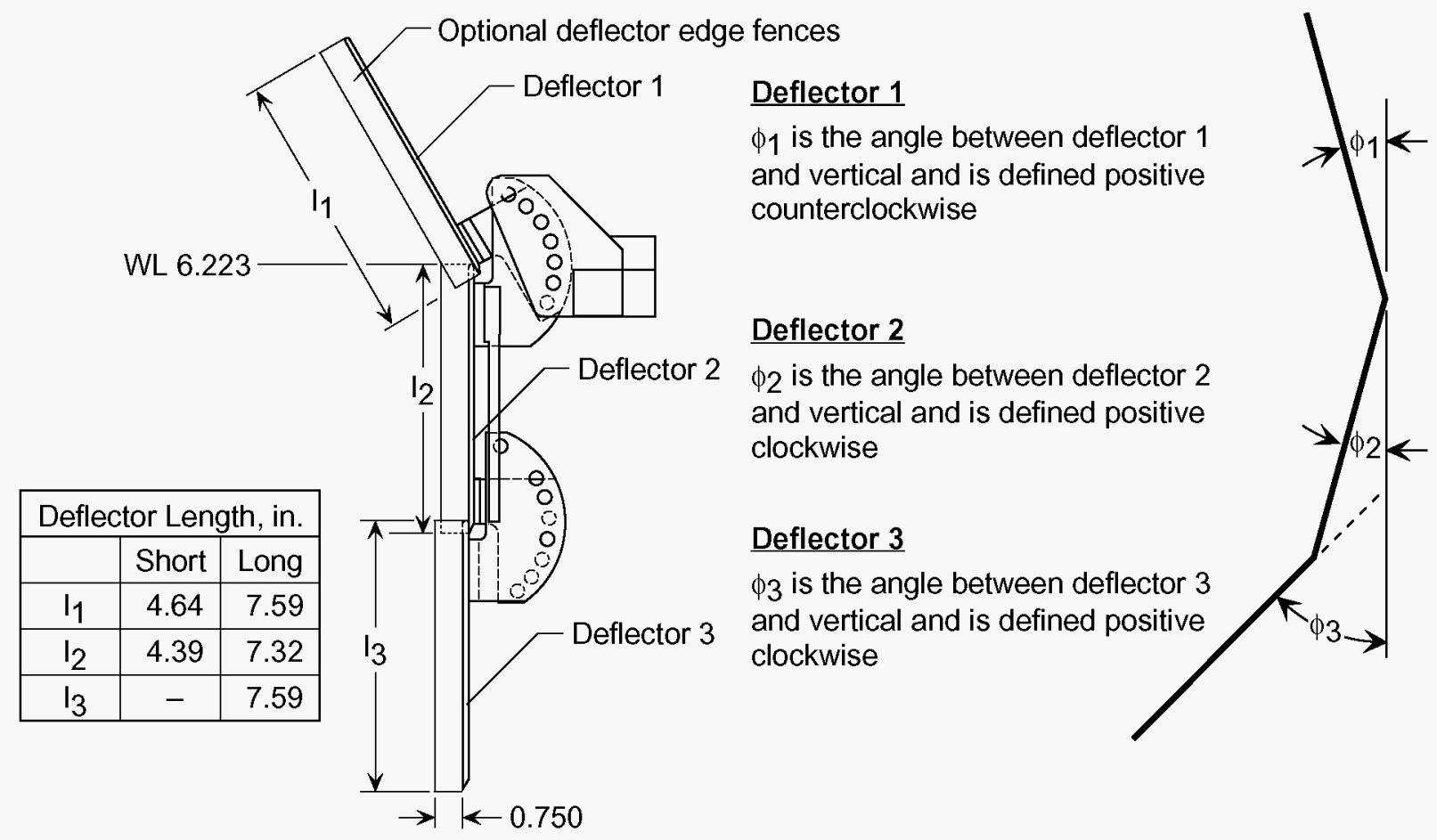

Figure 5. Sketch showing details of deflector system. 


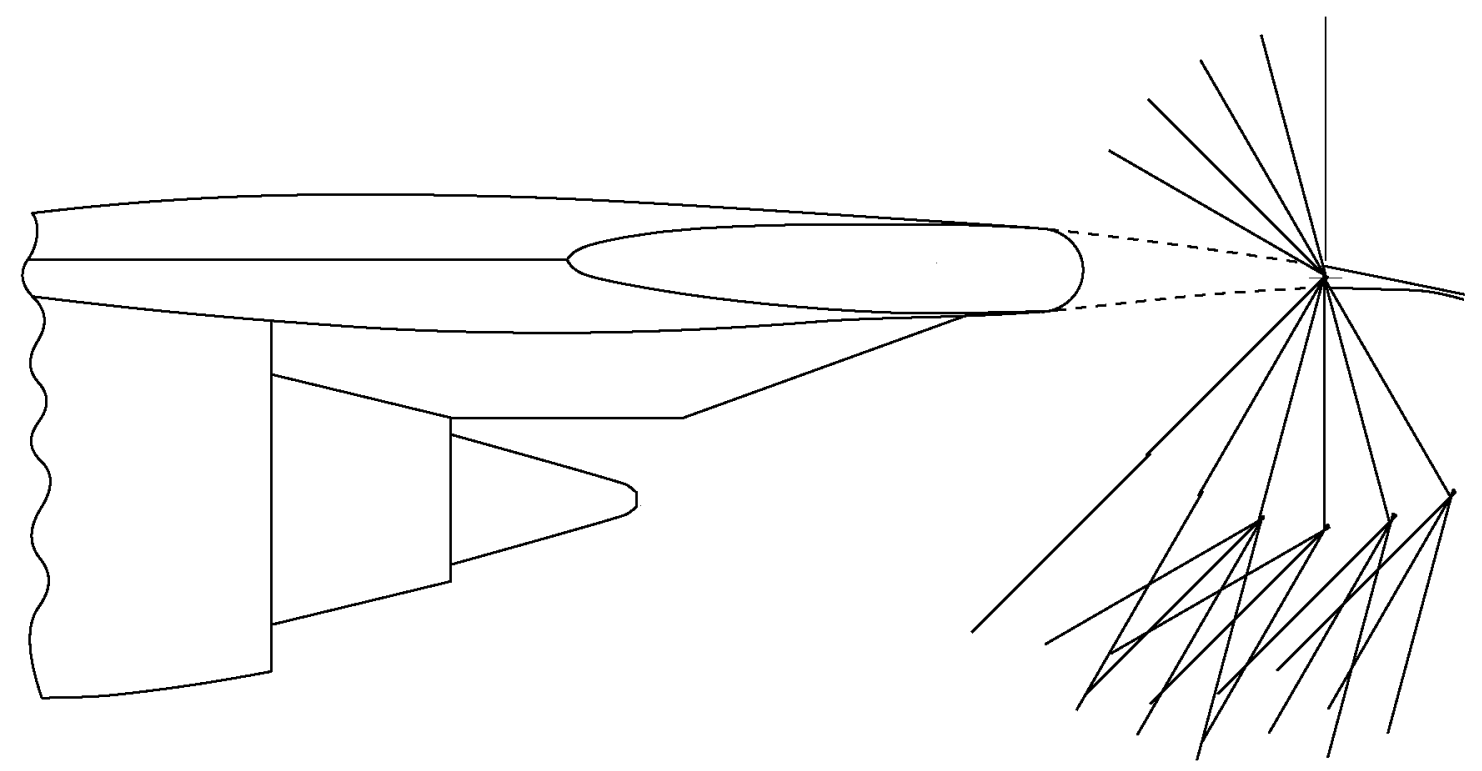

Figure 6. Sketch showing range of deflector angles tested.

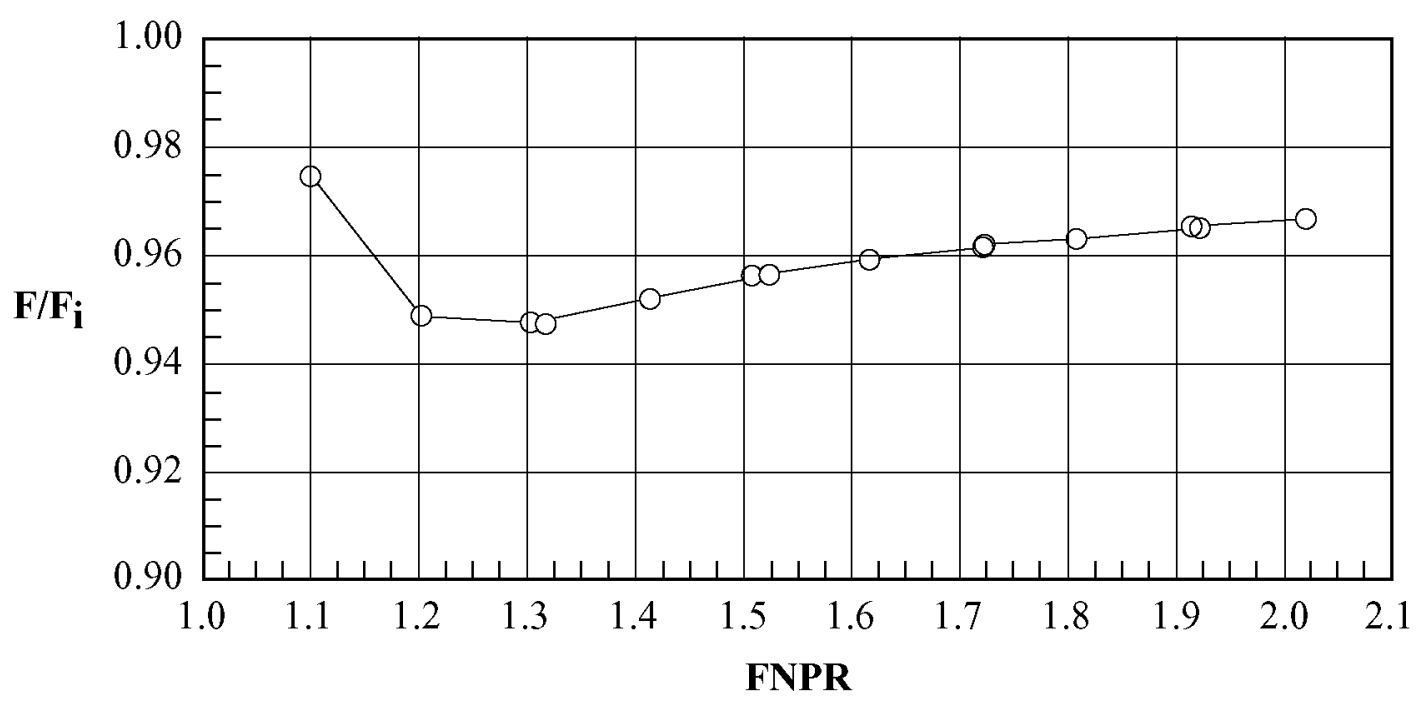

Figure 7. Overall nozzle thrust efficiency performance in forward thrust. 

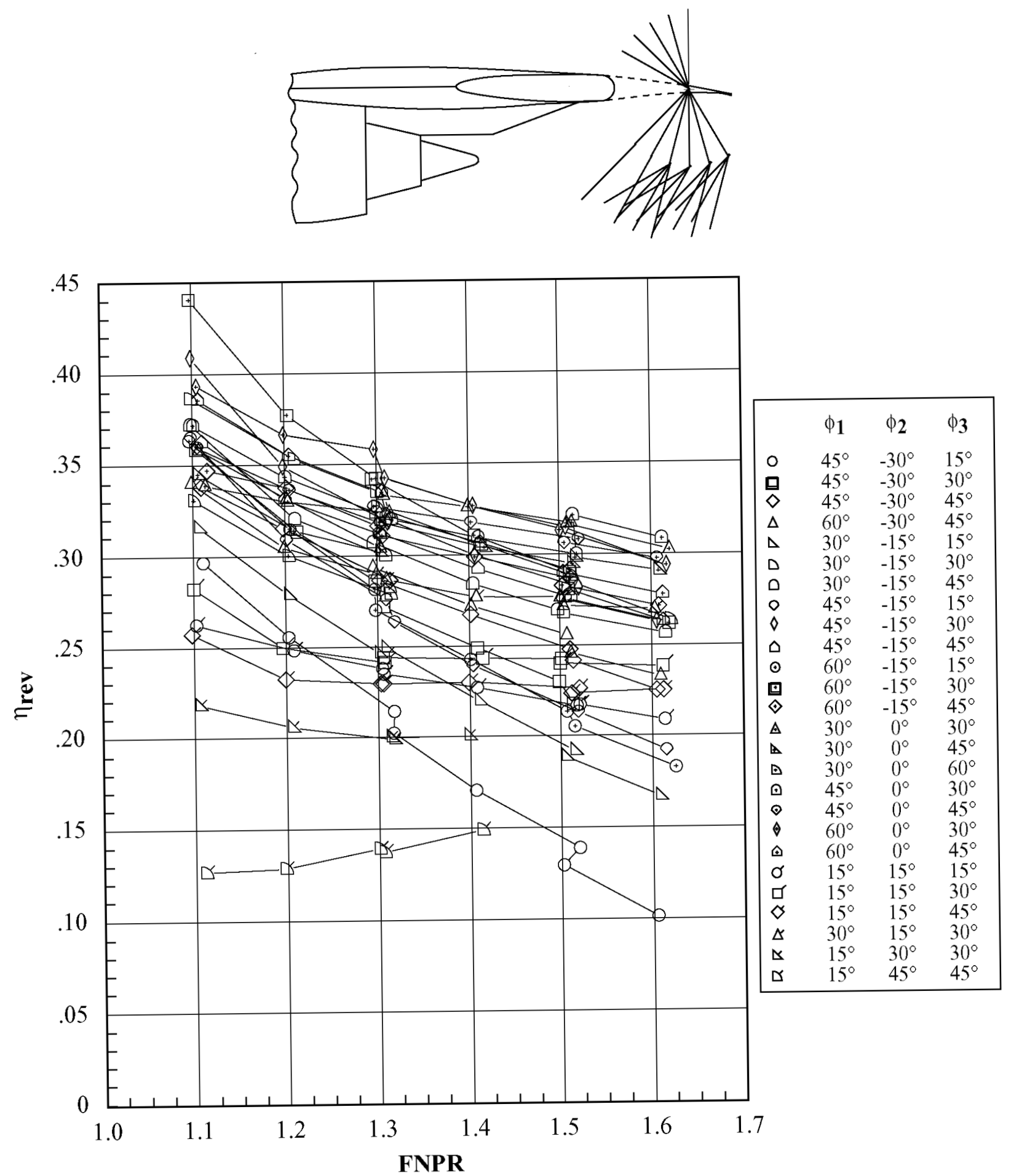

Figure 8. Summary of overall reverser effectiveness for wing-mounted reverser configurations with parallel deflector mount angle, long deflector chord length, and deflector edge fences installed. 


\begin{tabular}{|cccc|}
\hline & $\phi \mathbf{1}$ & $\phi_{2}$ & $\phi_{3}$ \\
$\circ$ & $30^{\circ}$ & $-15^{\circ}$ & $30^{\circ}$ \\
$\square$ & $45^{\circ}$ & $-15^{\circ}$ & $30^{\circ}$ \\
$\diamond$ & $60^{\circ}$ & $-15^{\circ}$ & $30^{\circ}$ \\
\hline
\end{tabular}
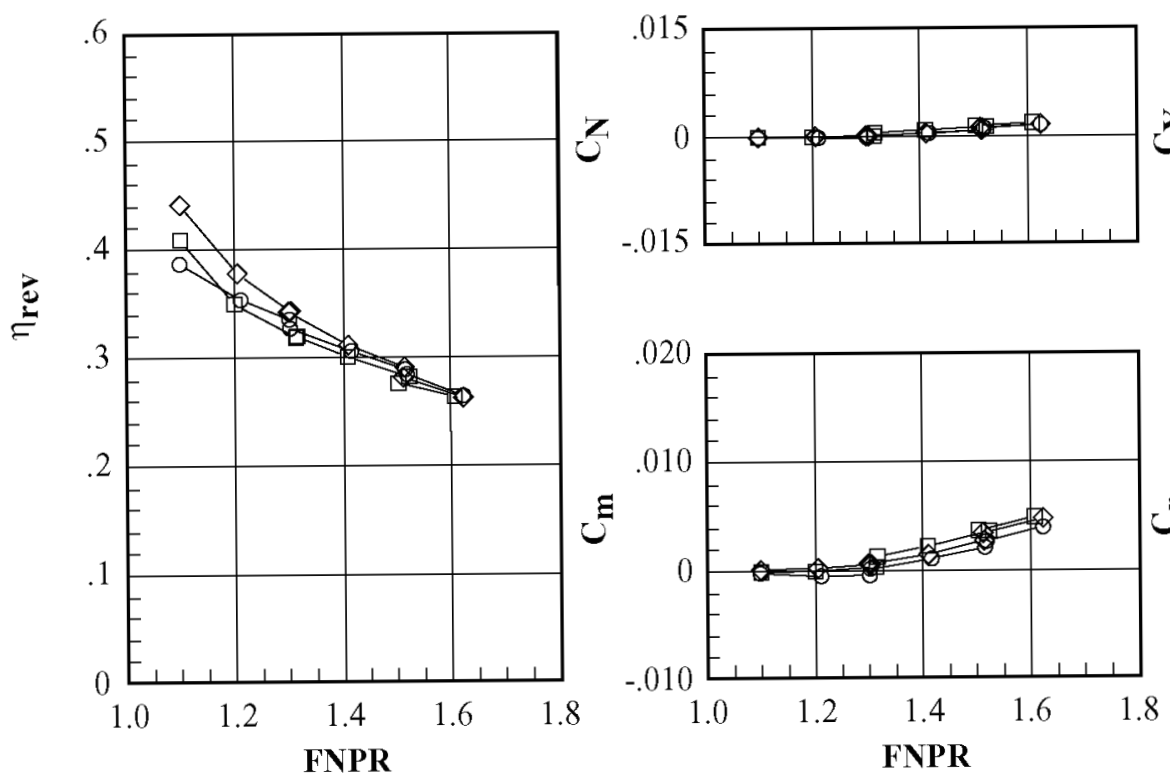

(a) $\phi_{2}=-15^{\circ}$.

\begin{tabular}{|cccc|}
\hline & $\phi_{1}$ & $\phi_{2}$ & $\phi_{3}$ \\
$\circ$ & $30^{\circ}$ & $0^{\circ}$ & $30^{\circ}$ \\
$\triangleright$ & $45^{\circ}$ & $0^{\circ}$ & $30^{\circ}$ \\
$\diamond$ & $60^{\circ}$ & $0^{\circ}$ & $30^{\circ}$ \\
\hline
\end{tabular}
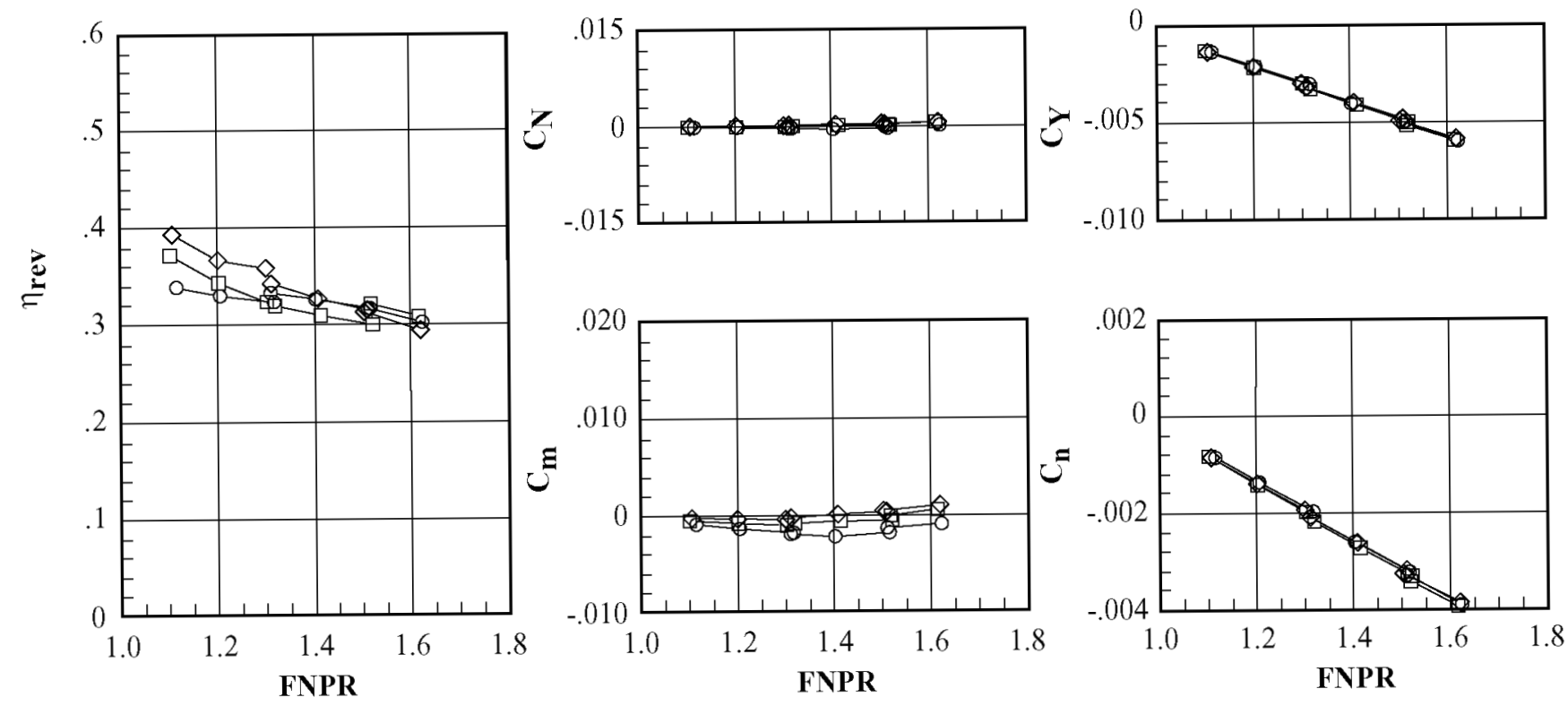

(b) $\phi_{2}=0^{\circ}$.

Figure 9. Effects of deflector 1 angle $\left(\phi_{1}\right)$ for wing-mounted reverser configurations with parallel deflector mount angle, long deflector chord length, and deflector edge fences installed; $\phi \mathbf{3}=30^{\circ}$. 


\begin{tabular}{|cccc|}
\hline & $\phi_{\mathbf{1}}$ & $\phi_{\mathbf{2}}$ & $\phi_{\mathbf{3}}$ \\
$\circ$ & $45^{\circ}$ & $-30^{\circ}$ & $30^{\circ}$ \\
$\square$ & $45^{\circ}$ & $-15^{\circ}$ & $30^{\circ}$ \\
$\diamond$ & $45^{\circ}$ & $0^{\circ}$ & $30^{\circ}$ \\
\hline
\end{tabular}
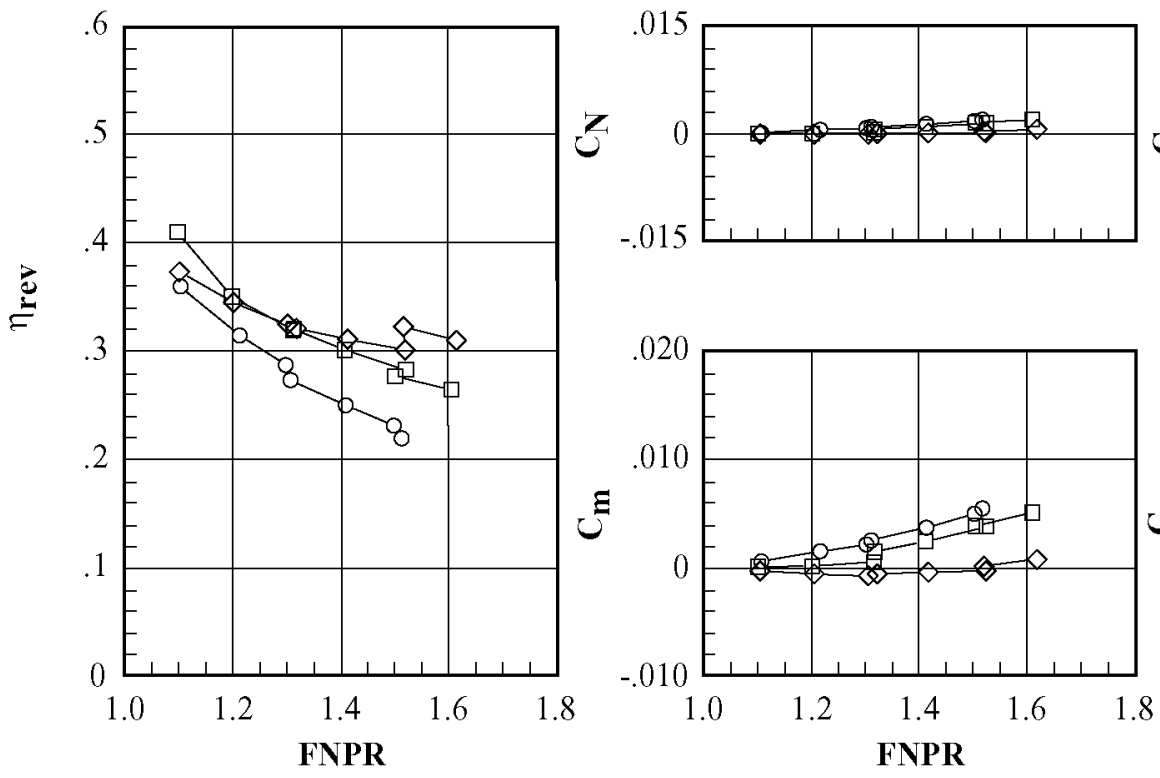
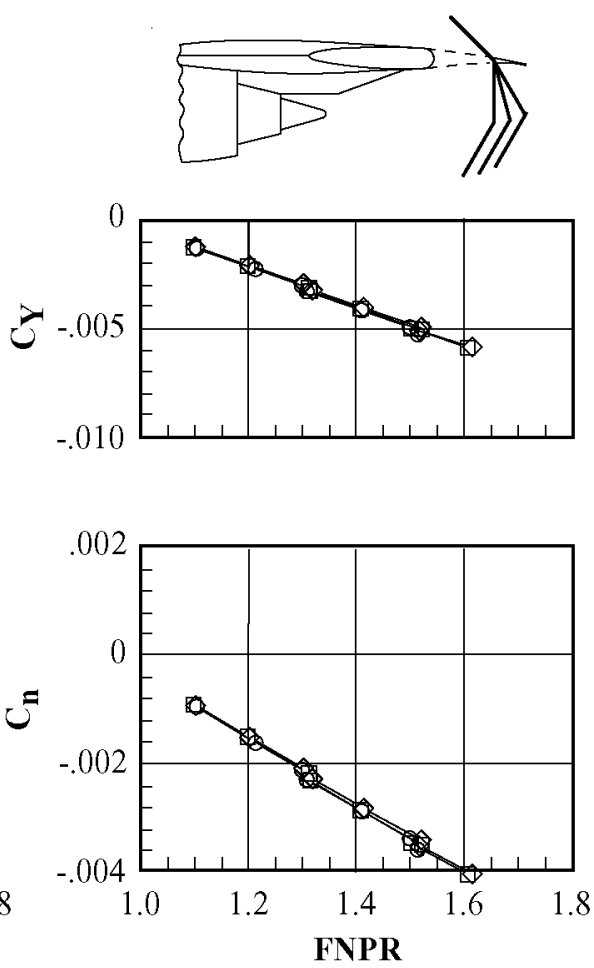

(a) $\phi 3=\mathbf{3 0}^{\circ}$.

\begin{tabular}{|cccc|}
\hline & $\phi_{1}$ & $\phi_{2}$ & $\phi_{3}$ \\
$\circ$ & $45^{\circ}$ & $-30^{\circ}$ & $45^{\circ}$ \\
$\square$ & $45^{\circ}$ & $-15^{\circ}$ & $45^{\circ}$ \\
$\diamond$ & $45^{\circ}$ & $0^{\circ}$ & $45^{\circ}$ \\
\hline
\end{tabular}
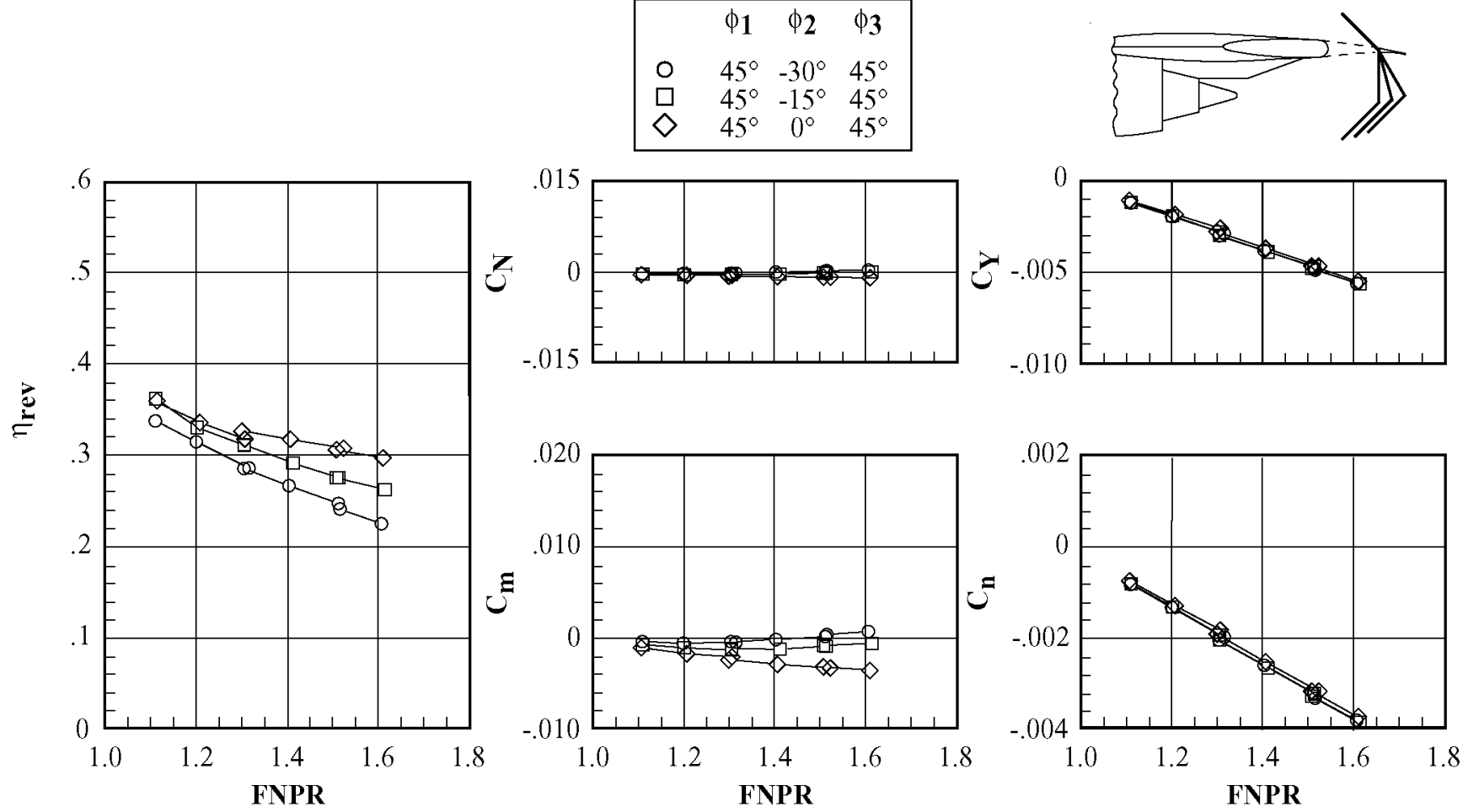

(b) $\phi \mathbf{3}=\mathbf{4 5 ^ { \circ }}$.

Figure 10. Effects of deflector 2 angle $\left(\phi_{2}\right)$ for wing-mounted reverser configurations with parallel deflector mount angle, long deflector chord length, and deflector edge fences installed; $\phi_{1}=45^{\circ}$. 


\begin{tabular}{|cccc|}
\hline & $\phi_{1}$ & $\phi_{2}$ & $\phi_{3}$ \\
$\circ$ & $60^{\circ}$ & $-15^{\circ}$ & $15^{\circ}$ \\
$\square$ & $60^{\circ}$ & $-15^{\circ}$ & $30^{\circ}$ \\
$\diamond$ & $60^{\circ}$ & $-15^{\circ}$ & $45^{\circ}$ \\
\hline
\end{tabular}
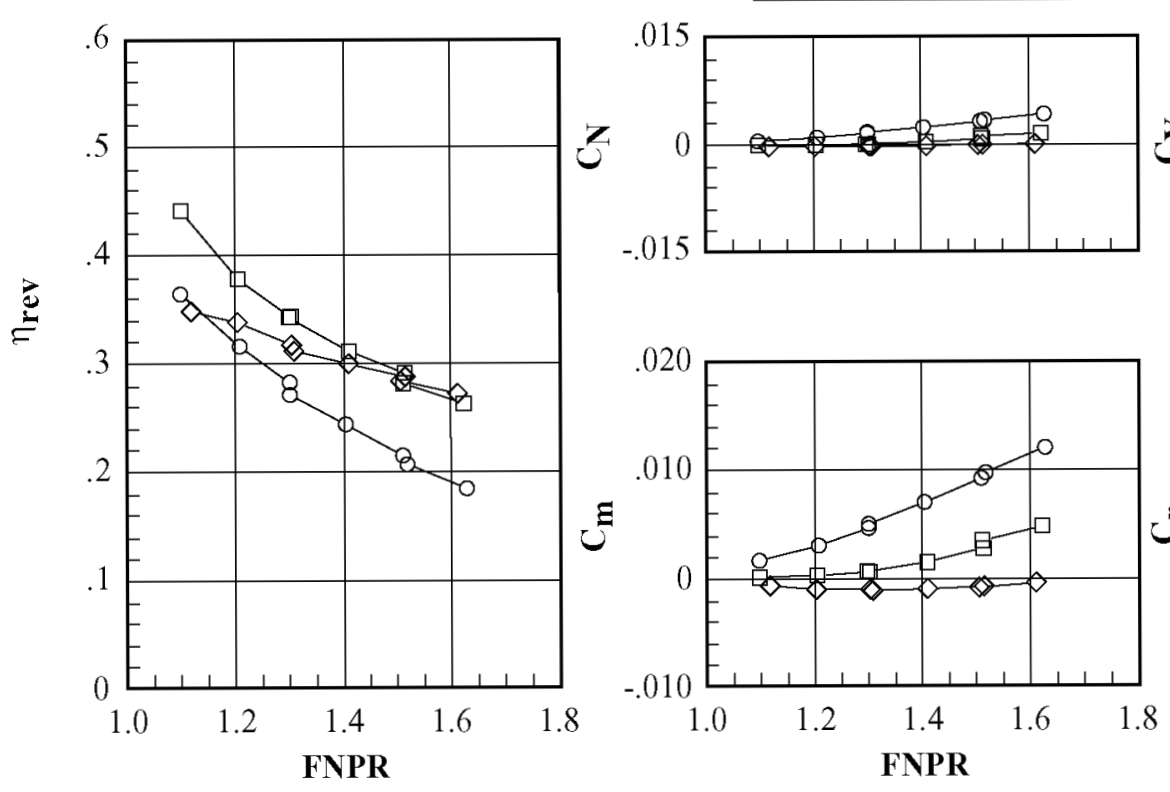

(a) $\phi_{2}=-15^{\circ}$.
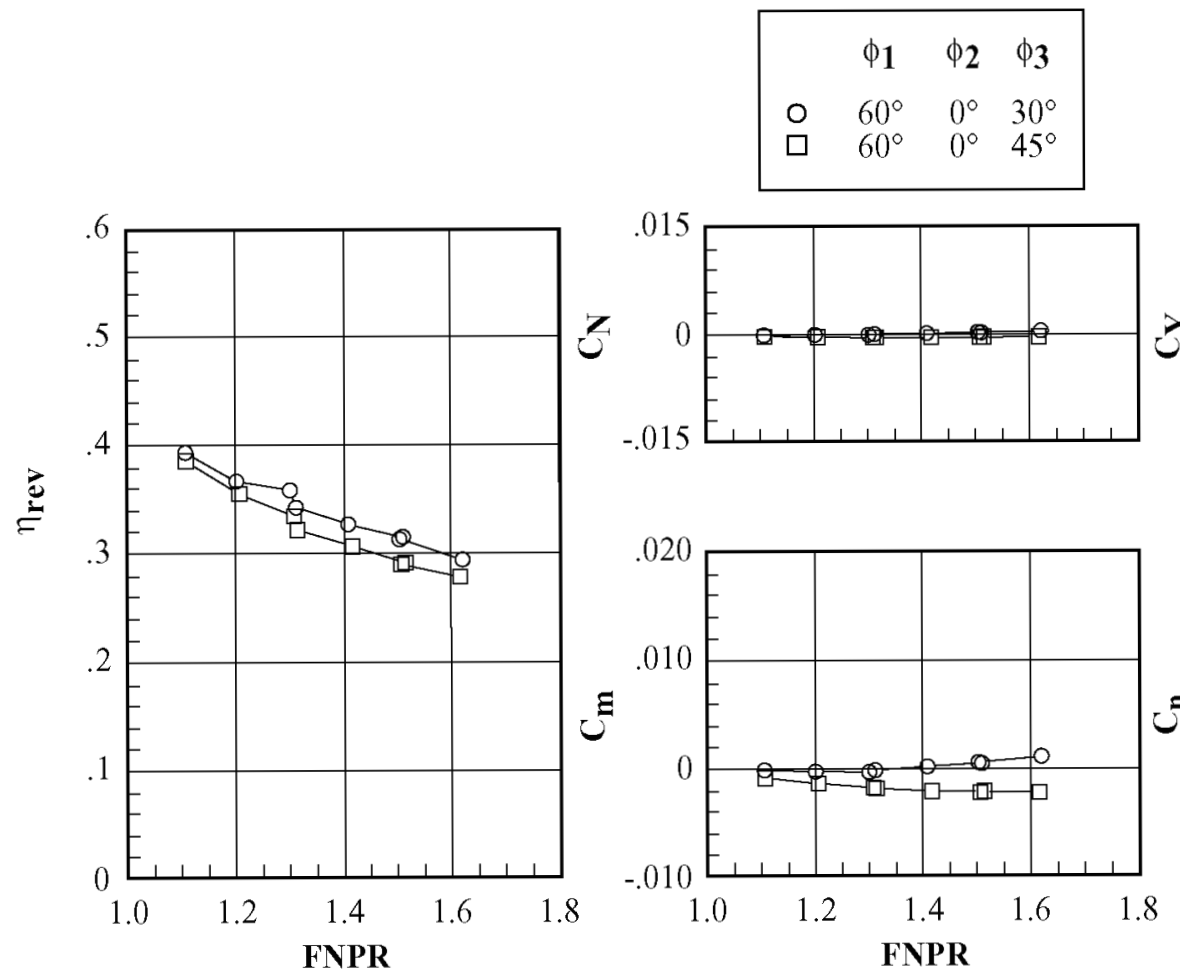

(b) $\phi_{\mathbf{2}}=\mathbf{0}^{\circ}$.
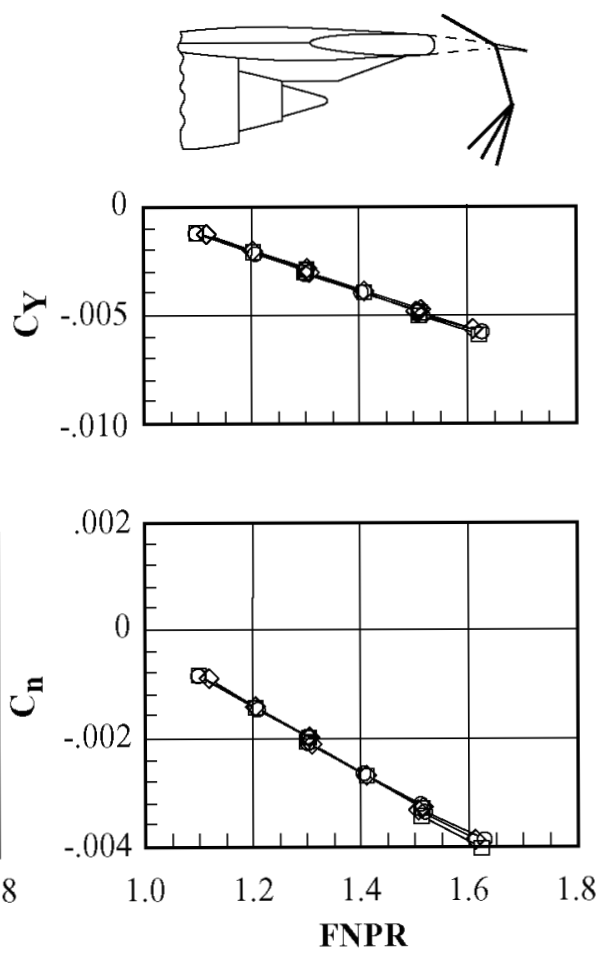

. 

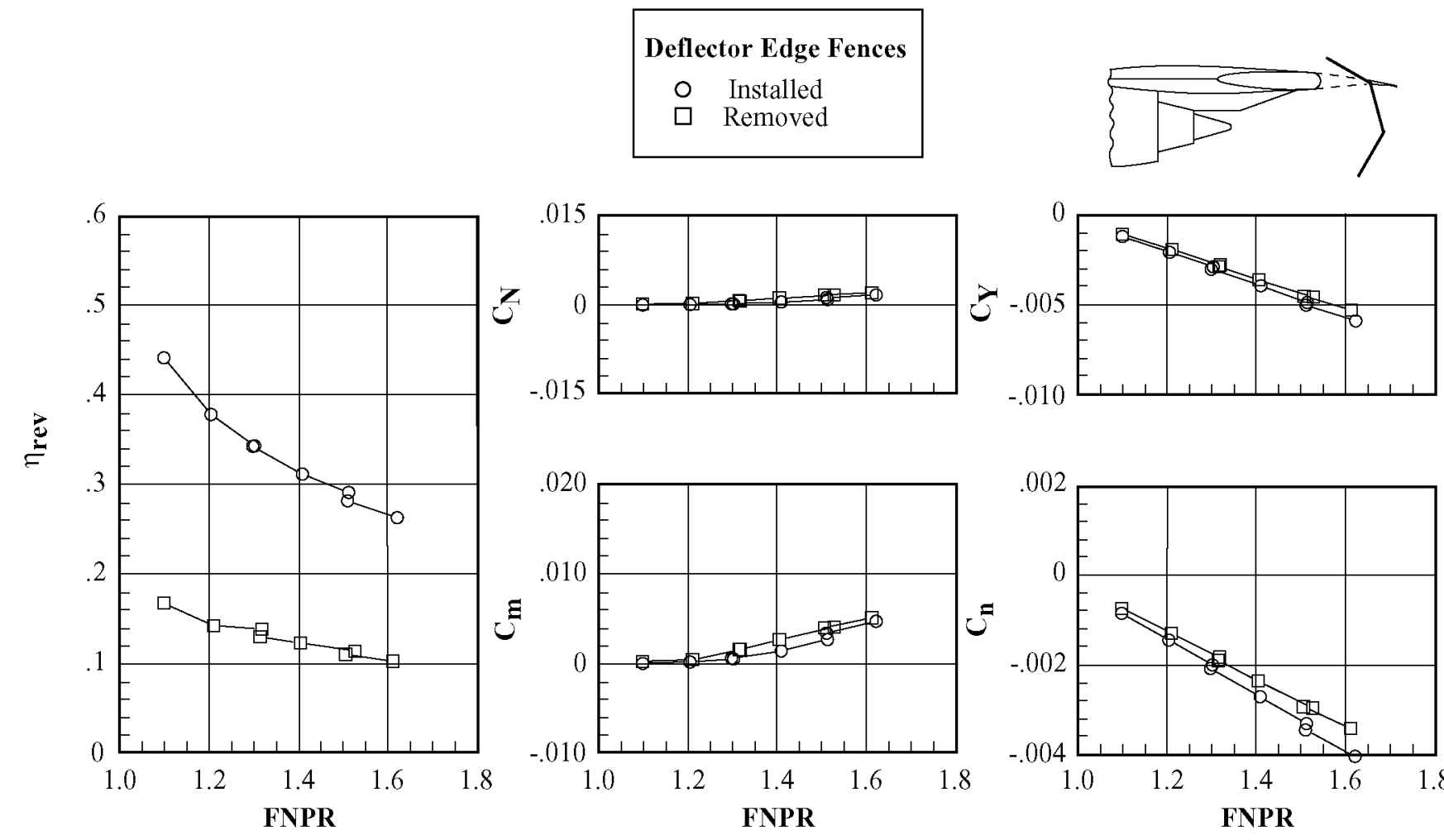

(a) $\phi_{2}=-15^{\circ}$.
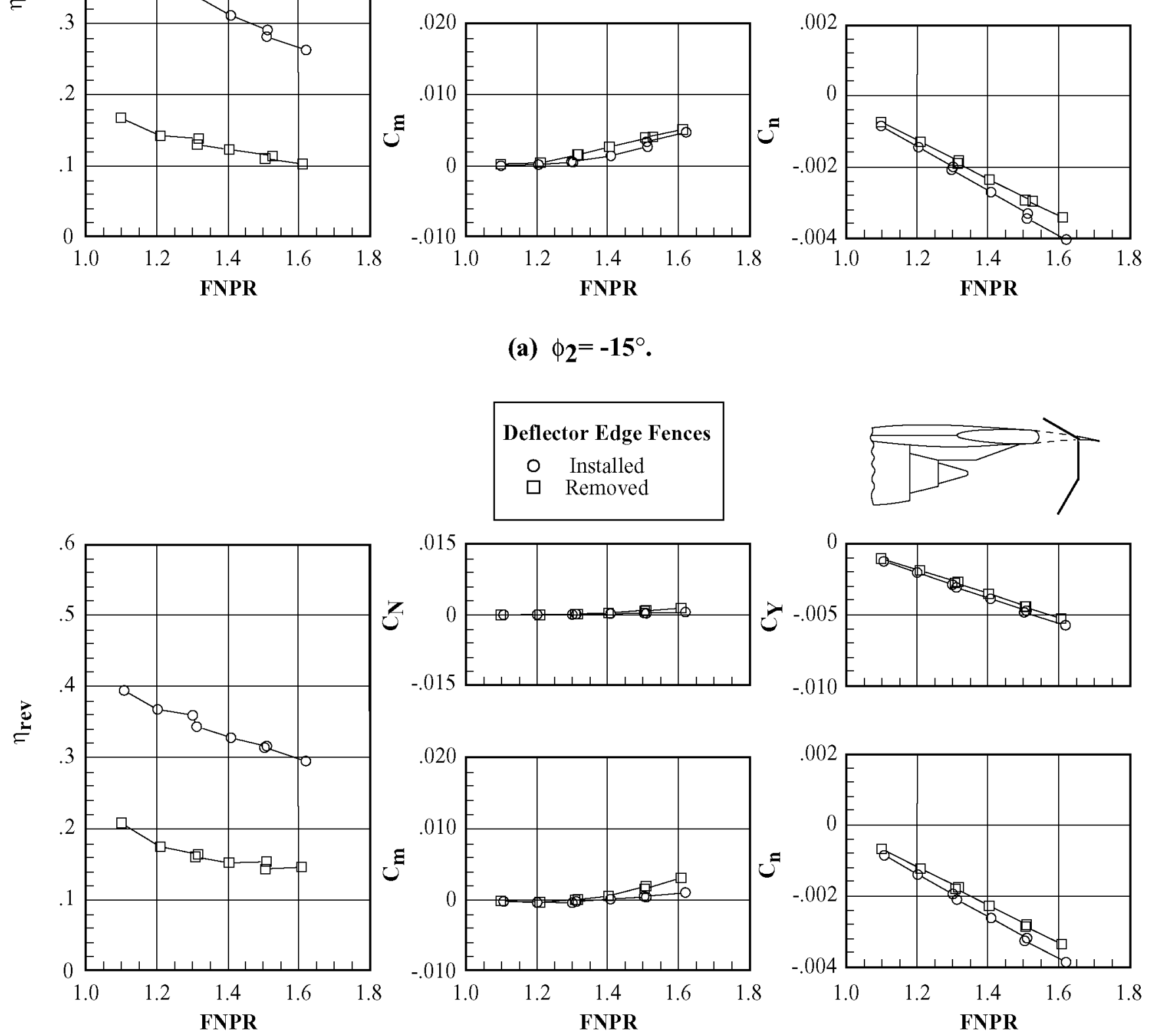

(b) $\phi_{\mathbf{2}}=\mathbf{0}^{\circ}$.

Figure 12. Effects of deflector fences for wing-mounted reverser configurations with parallel deflector mount angle and long deflector chord length; $\phi_{1}=60^{\circ}$ and $\phi_{3}=30^{\circ}$. 

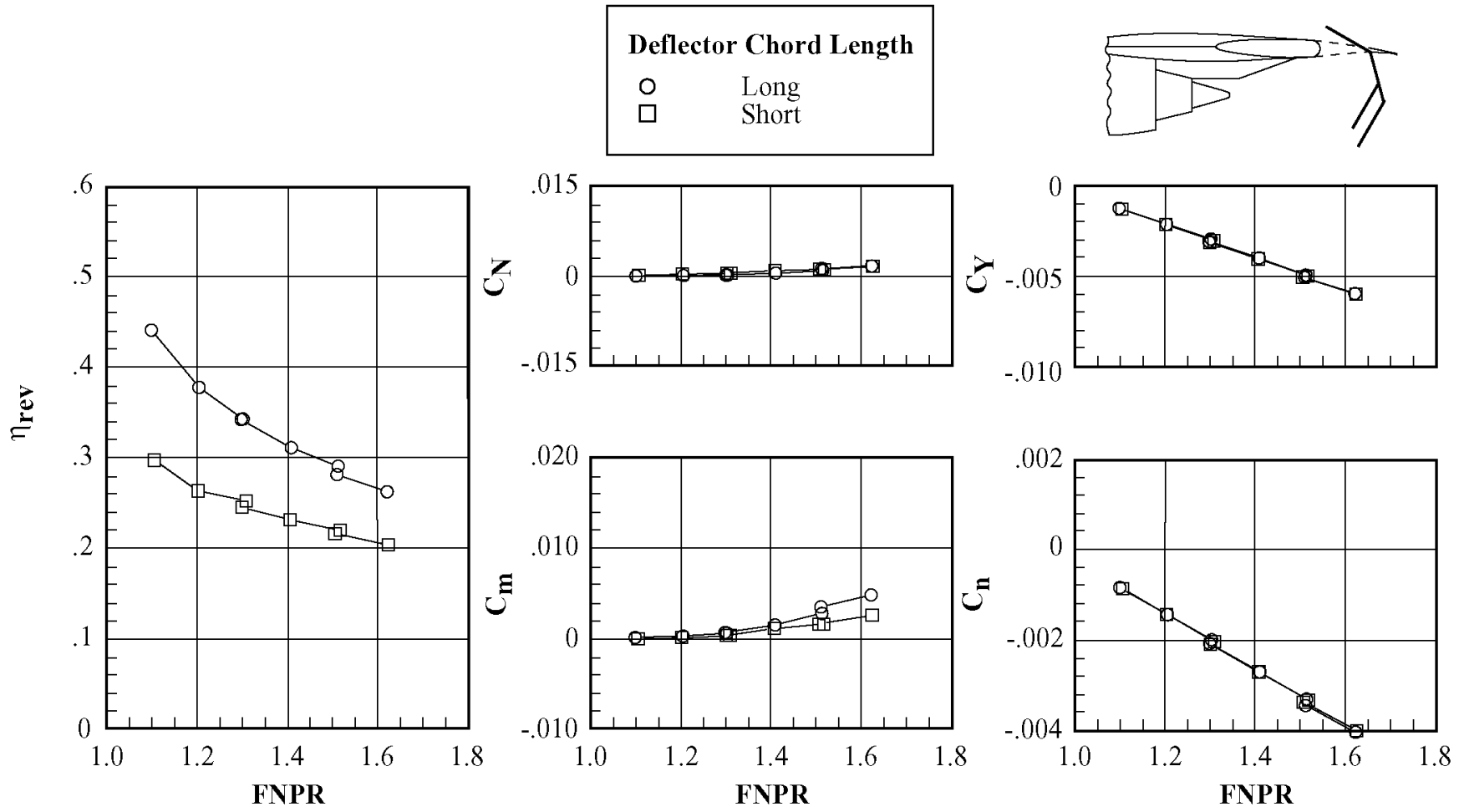

(a) $\phi_{2}=-15^{\circ}$.
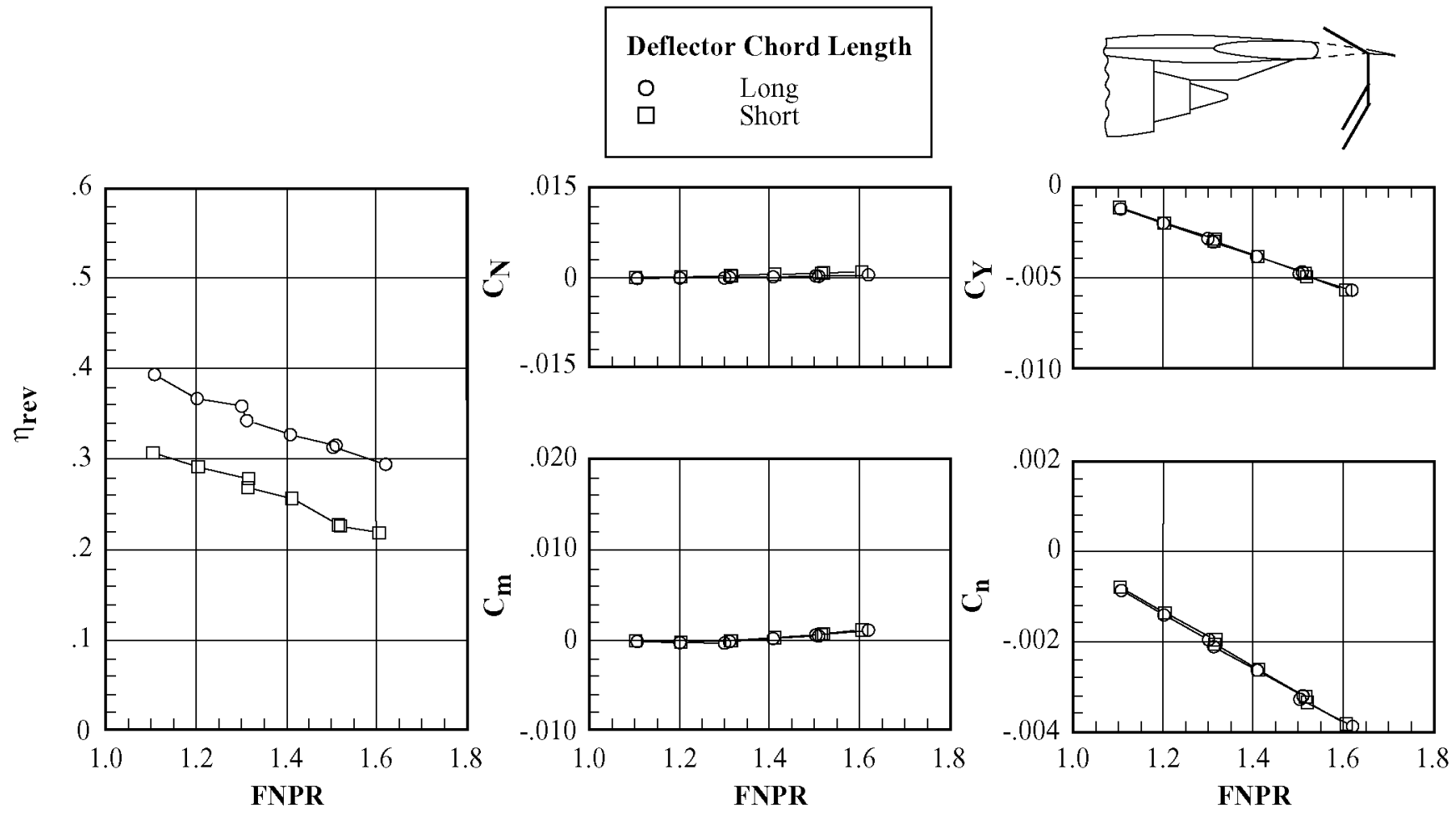

(b) $\phi_{\mathbf{2}}=\mathbf{0}^{\circ}$.

Figure 13. Effects of deflector chord length for wing-mounted reverser configurations with parallel deflector mount angle and deflector edge fences installed; $\phi_{1}=60^{\circ}$ and $\phi_{3}=30^{\circ}$. 

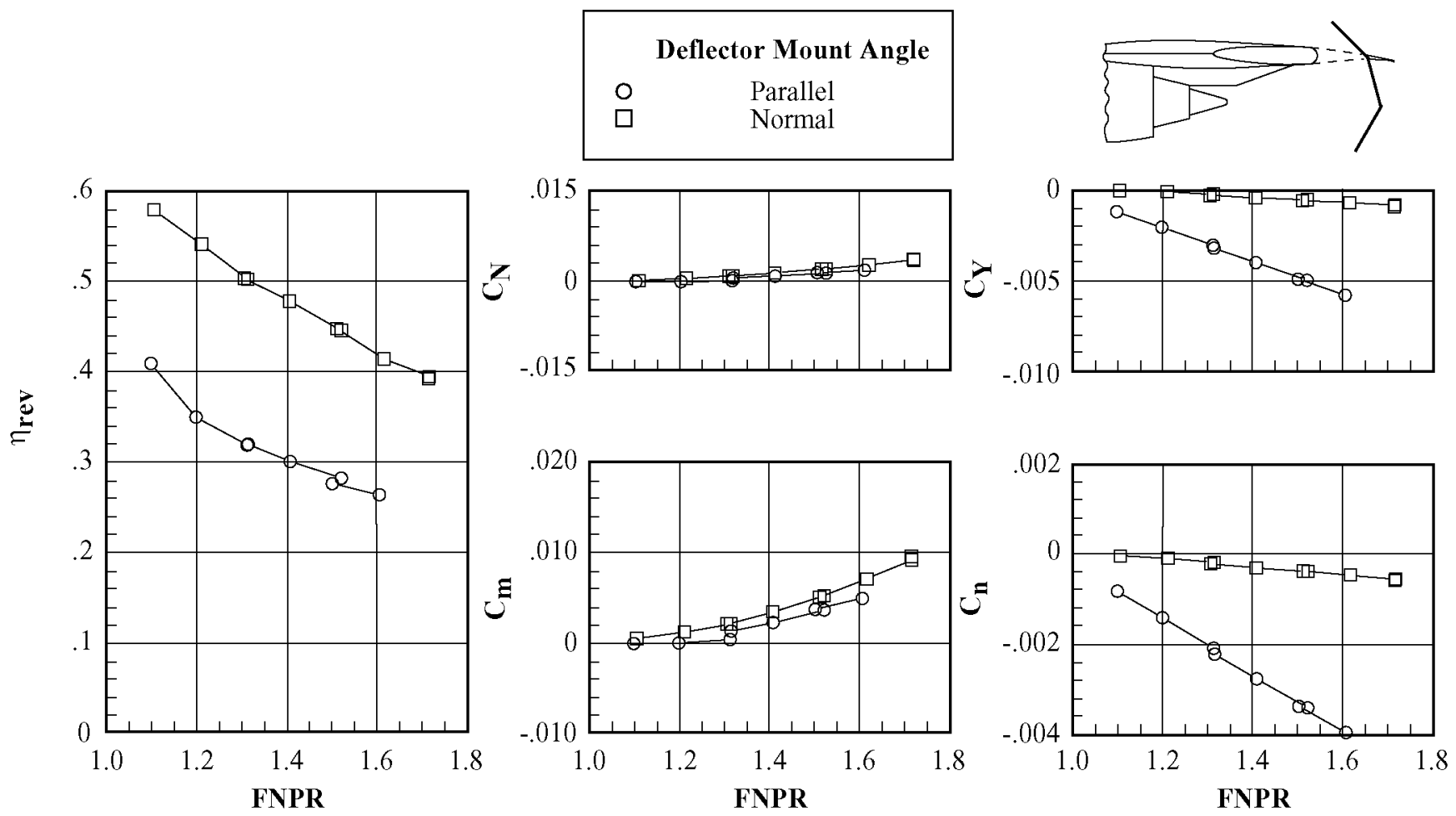

(a) $\phi_{1}=\mathbf{4 5}^{\circ}$ and $\phi_{2}=-15^{\circ}$.
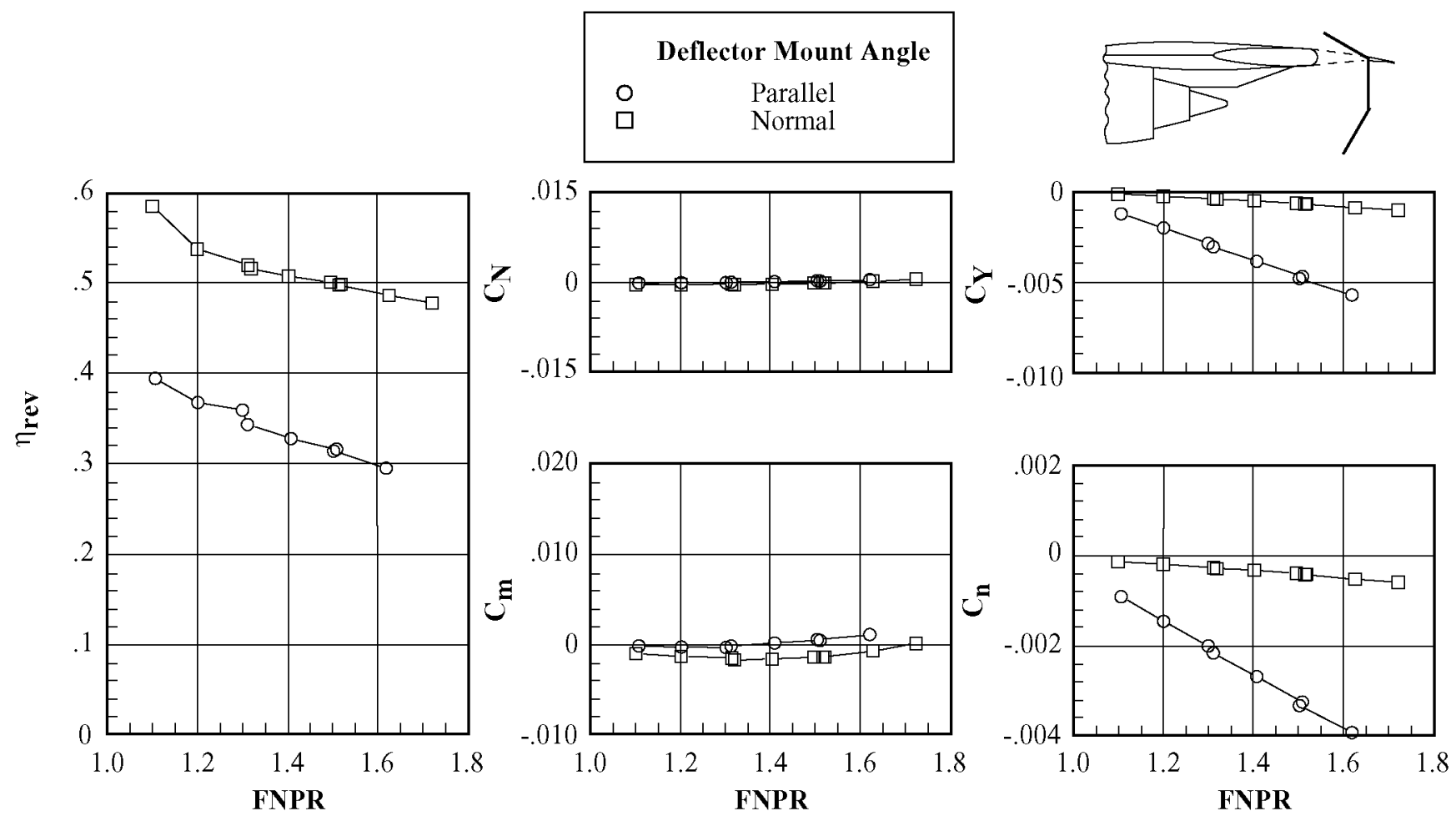

(b) $\phi_{1}=60^{\circ}$ and $\phi_{2}=0^{\circ}$.

Figure 14. Effects of deflector mount angle for wing-mounted reverser configurations with long deflector chord length and deflector edge fences installed; $\phi \mathbf{3}=30^{\circ}$. 